Article

\title{
Transcriptomic Insights into the Effect of Melatonin in Saccharomyces cerevisiae in the Presence and Absence of Oxidative Stress
}

\author{
Mercè Sunyer-Figueres ${ }^{+} \mathbb{\infty}$, Jennifer Vázquez ${ }^{\dagger}$, Albert Mas ${ }^{\oplus}$, María-Jesús Torija *(i) \\ and Gemma Beltran $\mathbb{D}$ \\ Departament de Bioquímica i Biotecnologia, Grup de Biotecnologia Enològica, Facultat d'Enologia, \\ Universitat Rovira i Virgili, C/Marcel-lí Domingo, 1. 43007 Tarragona, Catalunya, Spain; \\ merce.sunyer@urv.cat (M.S.-F.); jenvazk@gmail.com (J.V.); albert.mas@urv.cat (A.M.); \\ gemma.beltran@urv.cat (G.B.) \\ * Correspondence: mjesus.torija@urv.cat; Tel.: +34-977558442 \\ + Both authors contributed equally to this work.
}

Received: 17 August 2020; Accepted: 28 September 2020; Published: 1 October 2020

\begin{abstract}
Melatonin is a ubiquitous indolamine that plays important roles in various aspects of biological processes in mammals. In Saccharomyces cerevisiae, melatonin has been reported to exhibit antioxidant properties and to modulate the expression of some genes involved in endogenous defense systems. The aim of this study was to elucidate the role of supplemented melatonin at the transcriptional level in S. cerevisiae in the presence and absence of oxidative stress. This was achieved by exposing yeast cells pretreated with different melatonin concentrations to hydrogen peroxide and assessing the entry of melatonin into the cell and the yeast response at the transcriptional level (by microarray and qPCR analyses) and the physiological level (by analyzing changes in the lipid composition and mitochondrial activity). We found that exogenous melatonin crossed cellular membranes at nanomolar concentrations and modulated the expression of many genes, mainly downregulating the expression of mitochondrial genes in the absence of oxidative stress, triggering a hypoxia-like response, and upregulating them under stress, mainly the cytochrome complex and electron transport chain. Other categories that were enriched by the effect of melatonin were related to transport, antioxidant activity, signaling, and carbohydrate and lipid metabolism. The overall results suggest that melatonin is able to reprogram the cellular machinery to achieve tolerance to oxidative stress.
\end{abstract}

Keywords: yeast; melatonin; oxidative stress; antioxidant; hydrogen peroxide; bioactive compound; hypoxia; mitochondria

\section{Introduction}

Melatonin (N-acetyl-5-methoxytryptamine; Mel) is a versatile indolamine that is best known as a neurohormone in vertebrates. Since it was first discovered in the bovine pineal gland [1], it has been found in most living organisms [2]. In humans, melatonin has numerous physiological functions, such as regulating circadian rhythms and synchronizing the reproductive cycle, and it exhibits anti-aging, antioxidant and anti-inflammatory activities. It can even modulate a variety of neural, endocrine and immune functions [3,4].

Since Sprenger et al. [5] initially related melatonin production to Saccharomyces cerevisiae, several studies have reported the ability of yeasts to synthetize melatonin during alcoholic fermentation, with levels in wine ranging bewteen $0.3-1800 \mathrm{nM}$ [6-12]. Little information on melatonin biosynthesis in yeast is available. Although a synthetic route similar to that described for vertebrates was initially 
reported [5], Muñiz-Calvo et al. [13] recently proposed a putative biosynthetic pathway including some steps described in plants, such as the synthesis of serotonin from tryptophan through tryptamine instead of 5-hydroxytryptophan. Another issue that remains to be deciphered is the physiological role of melatonin in yeasts. Recent studies have demonstrated a protective function of melatonin against oxidative stress and UV radiation [14-16] and indicated a hypothetical role as a signaling molecule [7]. The recent finding that melatonin interacts with glycolytic proteins during alcoholic fermentation reinforces the latter role, which seems to be linked to fermentative metabolism $[17,18]$.

Oxidative stress is provoked by an imbalance in reactive oxygen species (ROS) resulting in ROS-mediated molecular and functional impairment and ultimately leading to cell death. To prevent these effects, cells employ antioxidant defense mechanisms in which enzymatic and nonenzymatic systems take part, neutralizing free radicals before they affect essential elements of the cell [19-21]. In yeast, exogenously applied melatonin has been reported to protect various biomolecules from damage caused by free radicals both directly, by scavenging ROS, and indirectly, by decreasing oxidized glutathione and activating genes that are involved in the oxidative stress response, such as glutathione/glutaredoxin, thioredoxin, catalase and superoxide dismutase genes $[15,16]$. ROS produce changes in the lipid bilayer composition resulting in lipid peroxidation, which is correlated with membrane disintegration and cell death. Recently, it has been shown that under oxidative stress, Saccharomyces takes advantage of melatonin supplementation by reducing the lipid peroxidation provoked by ROS, leading to an increase in total fatty acids and a higher proportion of unsaturated fatty acids, resulting in a higher tolerance to hydrogen peroxide $\left(\mathrm{H}_{2} \mathrm{O}_{2}\right)$ [15].

In humans, the action of melatonin is mitochondrion targeted, as the electron transport chain (ETC), where higher ROS production occurs, is located in the mitochondria [22]. Therefore, melatonin not only reduces ROS damage by scavenging ROS and increasing antioxidant enzyme activities but also improves the efficiency of the ETC and ATP production (reviewed in Reiter et al. [23]). Zampol and Barros [24] revealed that the addition of melatonin to yeast cells improved respiration when the cells were challenged with a compound that induces oxidative stress (menadione), mainly by affecting complex IV activity, suggesting that melatonin may also exhibit mitochondrion-specific activity in yeast.

S. cerevisiae exhibits a number of inducible adaptive stress responses to oxidants such as $\mathrm{H}_{2} \mathrm{O}_{2}$, superoxide anions and lipid peroxidation products. The oxidative stress responses are regulated at the transcriptional level, and there is considerable overlap between them and the stress responses associated with other types of stresses (general stress response) [20,21]. Thus, the oxidative stress response is not mediated by an isolated linear metabolic or signaling pathway. Instead, cells are able to reprogram gene expression to optimize signal transduction for more efficient and effective adaptation, setting up a general stress response that encompasses a much larger stress signaling network and integrating information from many pathways [25-27]. The physiological changes induced in yeast by melatonin supplementation and the ways in which yeast cells respond to oxidative stress suggest that melatonin might be involved in multiple biological processes in yeast, and it is interesting to investigate whether melatonin acts as a signaling molecule that triggers a molecular and physiological response to cope with stress situations. Therefore, obtaining an accurate idea of how melatonin supplementation modulates gene expression is critical for understanding the signaling events that it triggers.

To gain insight into the antioxidant role and regulatory mechanism of melatonin in yeast, we evaluated the effect of melatonin on gene transcription after analyzing the ability of yeast to incorporate exogenous melatonin into the cell. For this purpose, we measured intracellular melatonin and performed a transcriptomic study in a commercial wine yeast strain of S. cerevisiae, in the presence and absence of both melatonin and oxidative stress. After analyzing the results, we validated the effect of melatonin on the lipid composition and mitochondria via physiological studies. 


\section{Materials and Methods}

\subsection{Yeast Strain and Experimental Conditions}

The wine yeast QA23, a commercial strain of S. cerevisiae (Lallemand, Montreal, QC, Canada), was used in this study. Yeast precultures were prepared in YPD broth $[2 \%(w / v)$ glucose, $2 \%(w / v)$ peptone and $1 \%(w / v)$ yeast extract (Panreac, Barcelona, Spain)], incubated at $28{ }^{\circ} \mathrm{C}$ with orbital shaking (120 rpm) for $24 \mathrm{~h}$, and monitored by measuring the OD at $600 \mathrm{~nm}$. Then, an initial population of $5 \times 10^{5}$ cells $/ \mathrm{mL}\left(\mathrm{OD}_{600 \mathrm{~nm}}\right.$ 0.05) was inoculated into YPD broth (175 mL for melatonin quantification, $50 \mathrm{~mL}$ for transcriptomic assays, $300 \mathrm{~mL}$ for time course assays, $450 \mathrm{~mL}$ for lipid analysis and $60 \mathrm{~mL}$ for the quantification of mitochondria) with or without melatonin [TLC grade, purity $\geq 98 \%$, Sigma-Aldrich (St. Louis, MO, USA)] supplementation ( $5 \mu \mathrm{M}$; Mel and Control conditions, respectively) and grown until the cells reached the initial exponential phase $\left(\mathrm{OD}_{600 \mathrm{~nm}} 0.5-0.6\right)$ (designated time 0$)$. Then, sublethal oxidative stress was induced with $2 \mathrm{mM} \mathrm{H}_{2} \mathrm{O}_{2}$ ( $\mathrm{MelH}$ and $\mathrm{h}$ conditions, respectively), and samples were taken after $1 \mathrm{~h}$ by harvesting the cells via centrifugation at $28,672 \times g$ for $5 \mathrm{~min}$ at $4{ }^{\circ} \mathrm{C}$. Then, the pellet was washed with Milli-Q water (Q-PODTM Advantage A10, Millipore, Burlington, MA, USA) and stored at $-80^{\circ} \mathrm{C}$ until use. The variations in this general procedure are specified below. The melatonin and $\mathrm{H}_{2} \mathrm{O}_{2}$ concentrations were chosen on the basis of our previous study in the QA23 strain [15]. A culture with $25 \mu \mathrm{M}$ melatonin supplementation under stress conditions was added $(25 \mathrm{MelH})$ in the microarray analysis. Three biological replicates were employed in all assays.

\subsection{Intracellular Melatonin Quantification}

For intracellular melatonin quantification, $10^{8}$ cells were harvested from the samples at $0 \mathrm{~h}$ (just before stress induction) and $1 \mathrm{~h}$ after the stress induction by centrifugation at $4700 \times g$ for $15 \mathrm{~min}$. Intracellular melatonin quantification was performed as previously described by Morcillo-Parra et al. [17]. In brief, melatonin was extracted by adapting the boiling buffered ethanol method described by Gonzalez et al. [28] and quantified by liquid chromatography mass spectrometry using a liquid chromatograph coupled to a triple quadrupole mass spectrometer (LC-MS/MS Agilent G6410A; Agilent Technologies Inc., Santa Clara, CA, USA). In parallel, $10^{8}$ cells were dried at $28^{\circ} \mathrm{C}$ for $48 \mathrm{~h}$ to determine the dry weight of the samples, and the melatonin concentration was expressed as $\mathrm{nM} / \mathrm{mg}$ dry weight.

\subsection{Assessment of Global Gene Expression by Microarray Analysis}

RNA was isolated from $10^{7}$ cells from each condition (Control, Mel, H, MelH, 25MelH) using a TRIzol $^{\circledR}$ Plus RNA Purification Kit from Ambion Life Technologies (Woburn, MA, USA), following the instructions of the manufacturer, but the chloroform step was repeated twice before transferring the upper phase containing the RNA to a fresh RNase-free tube. Furthermore, a DNAse (Qiagen, Barcelona, Spain) incubation step at $37^{\circ} \mathrm{C}$ for $15 \mathrm{~min}$ was included to remove the remaining DNA. The RNA samples were quantified with a NanoDrop 1000 TM spectrophotometer (Thermo Scientific, Waltham, MA, USA), and their integrity was analyzed with an RNA 2100 Bioanalyzer (Agilent Technologies Inc.) using the RNA 6000 Nano kit and the Plant RNA Nano protocol in Agilent 2100 Expert software. Gene expression levels were assessed using a Yeast Gene Expression Microarray $(8 \times 15 \mathrm{~K}$ format $)$ containing 6256 S. cerevisiae probes. Fifteen samples (three biological replicates of each condition) were analyzed. Each sample was labeled with Cy3 and hybridized through one-color microarray-based exon analysis (Low Input Quick Amp WT Labeling kit protocol version 2.0, Agilent Technologies) according to the manufacturer's instructions.

\section{Microarray Data Analysis}

Agilent Scan Control version A.8.5.1 software was used to scan 3- $\mu$ m-resolution slides using the Agilent G2565CA Microarray Scanner System with SureScan High-Resolution Technology. Feature extraction version 12.0.1.1 software (Agilent Technologies) was used for data extraction. Statistical transcriptomic analysis for identifying significant changes between the conditions was performed 
using Gene Spring GX Software v.13.1.1 from Agilent Technologies. The signal for each spot was normalized at the $75 \%$ percentile, and the moderated t-test with Benjamini-Hochberg multiple testing correction was used to designate the differentially expressed genes. The genes that were differentially expressed between two conditions ( $p$-value $<0.05)$ were selected for further analysis: Venn diagrams were generated at the website http://bioinformatics.psb.ugent.be/webtools/Venn/, regulatory networks were generated with the PheNetic web tool [29] and the molecular functions, biological processes and cellular components were determined with Gene Ontology (GO) (CC-BY 4.0, [30]). The specific pathways involved in the differentially expressed genes were analyzed with the KEGG pathway mapping database [31], and significantly enriched pathways were determined with the DAVID tool [32,33]. The results of transcriptomic analysis were deposited in the Gene Expression Omnibus (GEO) repository, with GEO accession number: GSE154702 (https://www.ncbi.nlm.nih.gov/geo/query/ acc.cgi?acc=GSE154702).

\subsection{Gene Expression by qPCR Analysis}

The expression of genes of interest was evaluated via qPCR before stress $(0 \mathrm{~h})$ and after exposure to stress (1, 4, 12 and $24 \mathrm{~h}$ for Control and Mel; 0.5, 1, 4, 12, 24 and $36 \mathrm{~h}$ for $\mathrm{h}$ and MelH). RNA was isolated from $10^{7}$ cells using the Universal RNA Purification Kit from EURx (Gdańsk, Poland) with some modifications: to improve cellular lysis, cells were resuspended with a mixture of $1 \%$ $\beta$-mercaptoethanol in lysis buffer [PureLink RNA mini kit (Invitrogen, Carlsbad, CA, USA)], added to a $2 \mathrm{~mL}$ screw-cap tube with $1 \mathrm{~g}$ of $0.5 \mathrm{~mm}$-diameter glass beads, and lysed using a MBB-16 Mini-Beadbeater (BioSpec Products, Inc., Bartlesville, OK, USA) (5 cycles of $30 \mathrm{~s}$ in the Mini-Beadbeater $+30 \mathrm{~s}$ on ice). The suspension was centrifuged for $5 \mathrm{~min}$ at $21,952 \times \mathrm{g}$ at $4{ }^{\circ} \mathrm{C}$ and transferred to a homogenization spin column. Thereafter, the protocol was followed as recommended by the manufacturer, with optional on-column DNase digestion with DNase I from EURx. The RNA samples were quantified with a NanoDrop $1000 \mathrm{TM}$ spectrophotometer (Thermo Scientific) and stored at $-80^{\circ} \mathrm{C}$. The obtained RNA, together with that obtained as described in Section 2.3, was converted to cDNA to evaluate the expression of genes of interest by qPCR (Table 1). The samples were prepared as follows: $12 \mu \mathrm{L}$ of $320 \mathrm{ng} / \mu \mathrm{L}$ RNA, $1 \mu \mathrm{L}$ of an Oligo (dT)20 primer (Invitrogen), $1 \mu \mathrm{L}$ of dNTPs $(10 \mathrm{mM}), 4 \mu \mathrm{L}$ of buffer, $1 \mu \mathrm{L}$ of DTT and $1 \mu \mathrm{L}$ of SuperScript IV Reverse Transcriptase (Invitrogen), and amplification was performed according to the instructions of the manufacturer using a 2700 Thermal Cycler (Applied Biosystems, Waltham, MA, USA) and stored at $-20^{\circ} \mathrm{C}$.

Table 1. Primers used in this study for the analysis of gene expression by qPCR.

\begin{tabular}{|c|c|c|}
\hline Gene Name & Nucleotide Sequence of Forward Primer $\left(5^{\prime}\right.$ to $\left.3^{\prime}\right)$ & Nucleotide Sequence of Reverse Primer $\left(5^{\prime}\right.$ to $\left.3^{\prime}\right)$ \\
\hline ACT1 & TGGATTCCGGTGATGGTGTT & CGGCCAAATCGATTCTCAA \\
\hline ADY2 & TTTCAGCCTTCGCGTTGAC & CTTGCGCTCTCGCATTGA \\
\hline ATP20 & GGGTCTTCAACCACCAACTGTT & GGCTCTGCTTATAAAGGTTCGAAT \\
\hline CIS1 & CCCATCGGGTTAGTTTCAAAAA & GACATGCTACCCACTCTGCAATAG \\
\hline $\operatorname{COX} 2$ & TCGTTGTAACAGCTGCTGATGTT & CCAGGAGTAGCATCAACTTTAATACCT \\
\hline GDH3 & CACCGGGTTCGGCTTAGTT & GCCGTTTGTTGCATAATCGA \\
\hline HEM2 & TTCCGCTATTCATCTCCGATAATCCAG & ACAGACATCGCAAATAATATACAGTTCAGG \\
\hline MGA1 & ATGGGCAGTCCCGTCCATTACT & TCGCATCATGTTCACCGTGGGT \\
\hline MMT1 & GCGTTGTTTGCGGATGCTA & GCAAAGTCAACAAGTCAGAAACCA \\
\hline SDH6 & АCTTCACCACCATTGAACACTTGT & GGGTGTGAAAAGGTGGCAATT \\
\hline SRX1 & CCTGTGTTGGATCCTCAA & GGCATAATATAGCGTCTGTC \\
\hline TAF10 & ATATTCCAGGATCAGGTCTTCCGTAGC & GTAGTCTTCTCATTCTGTTGATGTTGTTGTTG \\
\hline
\end{tabular}


The primers for each evaluated gene (Table 1) were designed using Primer Express software (Primer Express 3.0 Applied Biosystems), and we employed the genes ACT1, HEM2 and TAF10 as endogenic controls. All primers were supplied by Invitrogen, and a standard curve was performed for each pair of primers. qPCR was performed using $2 \mu \mathrm{L}$ of cDNA diluted 10-fold, $0.4 \mu \mathrm{L}$ of each primer, $0.08 \mu \mathrm{L}$ of ROX [SYBR Premix Ex Taq II (TaKaRa Bio Inc, Shiga, Japan)], $10 \mu \mathrm{L}$ of SYBR Green (SYBR Premix Ex Taq II) and 7.12 $\mu \mathrm{L}$ of sterile Milli-Q water. Amplification was conducted using a QuantStudio5 Real Time PCR system (Thermo Fisher Scientific) as follows: one cycle of $95^{\circ} \mathrm{C}$ for $1 \mathrm{~min}$ and 40 cycles of $95^{\circ} \mathrm{C}$ for $5 \mathrm{~s}$ and $60^{\circ} \mathrm{C}$ for $35 \mathrm{~s}$, followed by a dissociation step. Relative gene expression was calculated with Thermo Fisher Cloud software (Thermo Fisher Scientific) using the $2^{-\Delta \Delta C t}$ formula, where $\mathrm{Ct}$ is defined as the cycle at which fluorescence is determined to be statically significantly above background; $\Delta \mathrm{Ct}$ is the difference between the $\mathrm{Ct}$ of the gene of interest and the mean value for the endogenous controls, and $\Delta \Delta \mathrm{Ct}$ is the difference between the $\Delta \mathrm{Ct}$ values under the different conditions (see figure legends for relative expression details). Two biological replicates were analyzed under each condition.

\subsection{Analysis of Sterols, Fatty Acids and Phospholipids}

Yeast cell homogenates were obtained, and the protein content was quantified as described by Vázquez et al. [36]. Total lipids were extracted from cell fractions corresponding to $0.5 \mathrm{mg}, 1 \mathrm{mg}$ or $3 \mathrm{mg}$ of total cell protein for sterols, fatty acid (FA) or phospholipid (PL) assays, respectively, according to the method described by Folch et al. [37]. The composition of each lipid was determined as described by Vázquez et al. [36]. In brief, the composition of individual sterols was determined via gas-liquid chromatography-mass spectrometry (GC-MS) after the alkaline hydrolysis of the lipid extracts as described by Quail and Kelly [38]; to this aim a Hewlett-Packard 5690 Gas Chromatograph (Agilent Technologies) equipped with an HP 5972 mass selective detector using a capillary column (HP 5-MS; $30 \mathrm{~m} \times 0.25 \mathrm{mM}$ i.d. $\times 0.25 \mu \mathrm{m}$ film thickness) was employed. The FA composition was determined by gas-liquid chromatography (GLC) using a Hewlett-Packard 6890 gas chromatograph [39], and the PLs were first separated by two-dimensional thin layer chromatography (TLC) [40]. Later, individual PLs were scraped off the plate and quantified by estimating the amount of phosphates [41]. Two biological replicates were performed.

\subsection{Quantification of Mitochondria}

Mitochondria were stained with the fluorescent dye MitoTracker Green (Thermo Fisher Scientific). Cells were grown in YPD with or without melatonin $(5$ and $50 \mu \mathrm{M})$ until the cells reached the initial exponential phase, and oxidative stress was then induced (with 0,2 or $5 \mathrm{mM} \mathrm{H}_{2} \mathrm{O}_{2}$ ) for $1 \mathrm{~h}$. A total of $10^{7}$ cells were harvested and directly (without a freezing step) resuspended in $1 \mathrm{~mL}$ of PBS (phosphate-buffered saline) with a final concentration of $100 \mathrm{nM}$ MitoTracker Green and incubated for $10 \mathrm{~min}$ at room temperature protected from light. Fluorescence was measured via flow cytometry, and data acquisition was performed with FloMax software (Quantum Analysis GmbH, Münster, Germany) and processed with WinMDI 2.9 software (Joseph Trotter, Salk Institute for Biological Studies, La Jolla, CA, USA). The mean fluorescence index (MFI) was calculated according to Boettiger et al. [42]: [(geometric mean (Gmean) of the positive fluorescence)-(Gmean of the control)]/(Gmean of the control).

\subsection{Data Analysis}

Data obtained from the intracellular melatonin quantification, lipid content, mitochondrial quantification and qPCR analyses were subjected to analysis of variance (ANOVA) and Tukey's post hoc test using GraphPad Prism 7 (GraphPad Software, San Diego, CA, USA) and XLSTAT 2019 software (NY, USA). All the results were considered statistically significant at a $p$-value $<0.05$. To merge standard deviations, the program "combine means and SDs into one group program" of the StatsToDo website (https://www.statstodo.com/index.php) was used. 


\section{Results and Discussion}

In previous studies, we analyzed the antioxidant effects of exogenous melatonin on S. cerevisiae at the physiological level $[15,16]$. Our data showed slight increases in ROS and oxidized glutathione under melatonin supplementation when no stress was induced. In contrast, when cells were under oxidative stress, melatonin activated some genes involved in the yeast antioxidant defense systems, thus reducing ROS accumulation and increasing cellular viability [16]. In this study, we wanted to investigate the effect of melatonin on the yeast global transcriptomic response to gain insight into its antioxidant role and regulatory mechanisms.

\subsection{Differential Gene Expression Profiling}

To obtain an overview of the gene expression profile associated with melatonin supplementation in S. cerevisiae, a comparative transcriptomic analysis was performed between cells that were grown with and without melatonin supplementation $(5 \mu \mathrm{M})$ and with and without oxidative stress exposure $(2 \mathrm{mM}$ $\mathrm{H}_{2} \mathrm{O}_{2}$ ) (Control, $\mathrm{Mel}, \mathrm{h}$ and $\mathrm{MelH}$ conditions). The overall results obtained from the transcriptomic analysis can be found in Datasets S1-S10: differentially expressed genes $(p$-value $<0.05)$ are listed in Datasets S1-S5, and the results for all genes are provided in Datasets S6-S10 and at the GEO repository (https://www.ncbi.nlm.nih.gov/geo/query/acc.cgi?acc=GSE154702). The numbers of genes showing significant changes in global gene expression (with a $p$-value $<0.05$ ) under each condition are represented in Figure 1. A total of 649 genes were differentially expressed under exogenous melatonin treatment (Mel vs. Control), mainly downregulated (422 genes), while oxidative stress resulted in the altered expression of 4427 genes (Figure 1A; h vs. Control). Among these genes, 3658 were affected by stress independent of the presence of melatonin (common to h vs. Control and MelH vs. Control but not Mel vs. Control) (Figure 1B,C). However, melatonin clearly altered the gene expression profile of stressed cells, with 775 genes being differentially expressed (MelH vs. H), most of which were upregulated (498 genes), in contrast with the downregulation effect of melatonin on expression in nonstressed cells (Figure 1A). Furthermore, the effect of the melatonin concentration under oxidative stress was evaluated by testing a higher concentration $(25 \mu \mathrm{M}$ melatonin, $25 \mathrm{MelH})$. Its effect was weak, with only 85 genes exhibiting altered expression due to the higher concentration of melatonin (Figure 1A, 25MelH vs. MelH, Datasets S5 and S10). Thus, $5 \mu \mathrm{M}$ melatonin was sufficient to modulate gene regulation in yeast cells.

Our results showed 189 genes were differentially expressed under all three conditions (Mel, H, $\mathrm{MelH}$ ) in comparison with the control (Figure $1 \mathrm{~B}(\mathrm{i})$, Figure $1 \mathrm{C}(\mathrm{j})$ ), most of which were downregulated and were involved in mitochondrial function (Table S1). Additionally, 24 genes were regulated by melatonin regardless of the stress treatment (common in Mel vs. Control and MelH vs. Control, Figure $1 \mathrm{~B}(\mathrm{a})$, Figure $1 \mathrm{C}(\mathrm{c})$ ). Most of them were also downregulated and were mainly involved in nutrient regulation (NRD1, SNZ2 and RGM1) or gene transcription (GCD14, NOG1 and NRD1) (Figure $1 \mathrm{E}(\mathrm{c})$ ). On the other hand, when we focused on the effect of melatonin in the cell, under stressed and nonstressed conditions, we found 69 genes that were commonly up- or downregulated by melatonin in both conditions (Figure 1D, groups e and f) and 22 genes that were regulated in opposite direction in stressed or nonstressed cells (Figure 1D, groups $g$ and $h$ ). The upregulated genes were involved in the response to ROS (including both metallothioneins, CUP1-1 and CUP1-2) and water deprivation, protein folding, oxidation-reduction process (COX1), copper binding (metallothioneins and CCC2), zinc homeostasis (IZH4) and the transport of maltose (MAL31), oligopeptides (OPT1) and ions (HSP30) (Figure 1D,E, group e, Table S1). The genes downregulated by melatonin were mainly related to transcription and the regulation of gene expression (Figure 1D,E, group $\mathrm{f}$, Table S1). On the other hand, several mitochondrial genes presented opposite behavior in relation to melatonin treatment; i.e., they were downregulated in nonstressed cells and upregulated in stressed cells, mainly being involved in the electron transfer chain and ATP synthesis, including genes related to cytochrome c oxidase (COX5A, COX8) and reductase activity (QCR9), ATP synthase (ATP14), and mitochondrial 
organization and stability. In this group, there were also genes related to thiamine metabolic processes and RNA processing (Figure 1D,E, group g, Table S1).

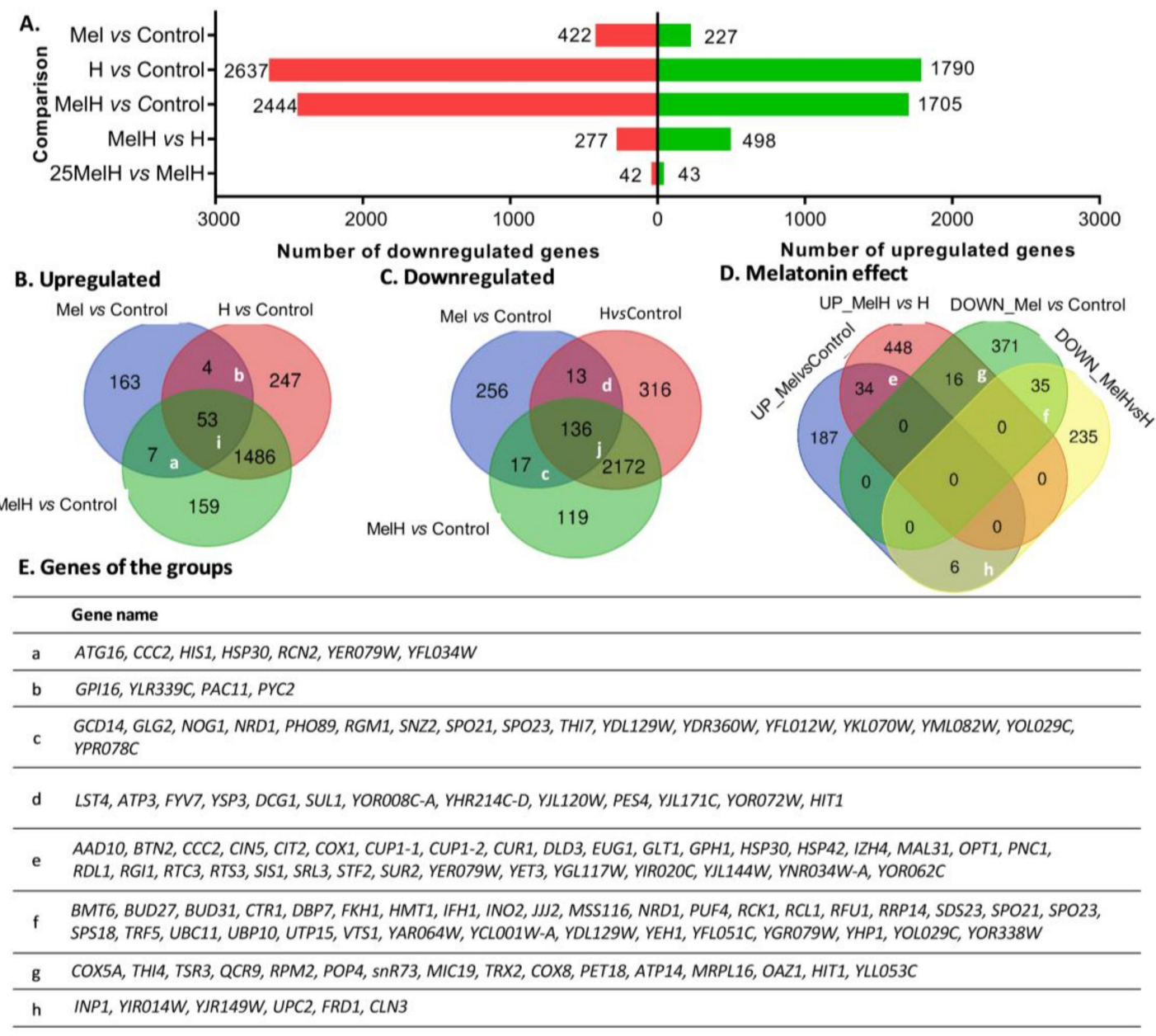

Figure 1. Distribution of differentially expressed genes in yeast cells grown with and without melatonin $(5 \mu \mathrm{M}$ or $25 \mu \mathrm{M})$, in stressed $\left(2 \mathrm{mM}\right.$ of $\mathrm{H}_{2} \mathrm{O}_{2}$ ) and in unstressed conditions (Control, Mel, MelH, $25 \mathrm{MelH}$ and $\mathrm{H}$ ). (A) The number of differentially expressed genes between different conditions (fold change $-1 \leq \mathrm{FC} \geq 1$; $p$-value $<0.05)$. (B,C) Venn diagram showing the number of common genes found among the Mel vs. Control, MelH vs. Control and h vs. Control comparisons (up- (B) and down (C) regulated genes). (D) Venn diagram showing the number of common genes found among the up- and downregulated genes identified in the Mel vs. Control and MelH vs. h comparisons. (E) List of genes in some groups indicated in (B-D). The list of genes and the GO enrichment analysis of all the groups is shown in Table S1.

\subsection{Classification of Differentially Expressed Genes into Functional Categories}

To understand the role of melatonin supplementation in yeast, GO enrichment analysis was performed to determine which molecular functions, biological processes, cellular components and pathways were overrepresented among the differentially expressed genes under the different conditions. In this work, we mainly focus on the results obtained under conditions with the addition of melatonin with or without stress. The overall results obtained from the GO enrichment analysis with the genes included in each category can be found in the Supplementary Materials (Datasets S11-S19). Figure 2 and Table 2 show the main biological annotations significantly associated with genes that were upregulated or downregulated by melatonin. 

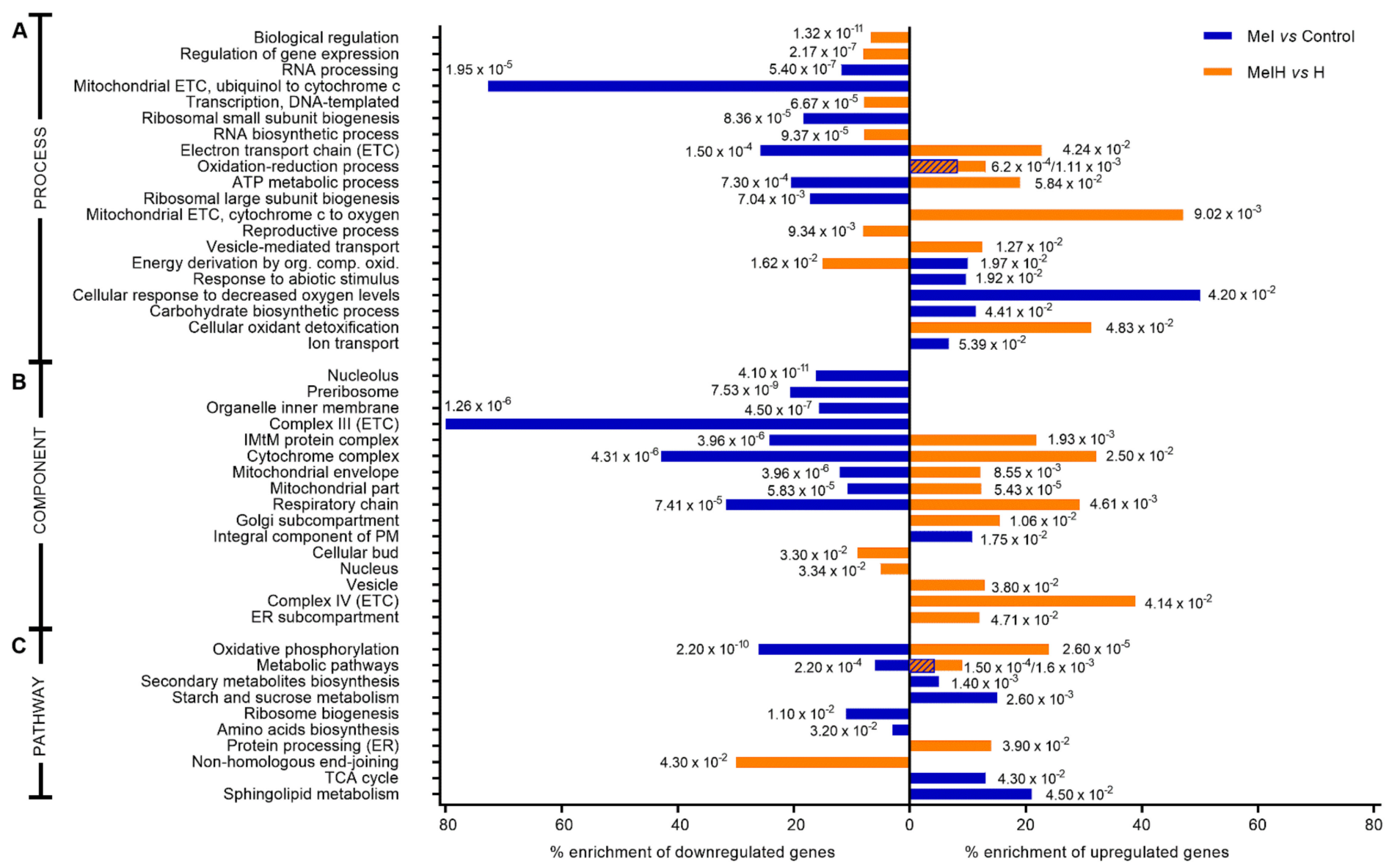

Figure 2. Categories enriched by differentially expressed genes that were up- (values to the left) and down- (values to the right) regulated ( $1 \leq$ fold change $\geq 1$; $p$-value $<0.05)$ among nonstressed (blue) and stressed (orange) $\left(2 \mathrm{mM} \mathrm{H}_{2} \mathrm{O}_{2}\right)$ cells in the absence or presence of melatonin $(5 \mu \mathrm{M})$. Percentages of enrichment are calculated as the ratio of the number of up- or downregulated genes in relation to the total number of genes involved in each molecular function or pathway in S. cerevisiae. The numbers correspond to the $p$-values. When two $p$-values are presented, the left one corresponds to Mel vs. Control and the right to MelH vs. $\mathrm{H}$. (A) Biological process function enrichment from Gene Ontology (GO) analysis, (B) cellular components enriched according to GO analysis, (C) pathway enrichment analyzed with the DAVID tool. Abbreviations: ETC, electron transport chain; ER, endoplasmic reticulum; TCA, citrate cycle, IMtM, inner mitochondrial membrane. 
Table 2. Molecular function enrichment according to the Gene Ontology (GO) analysis of differentially expressed genes that were up- or downregulated (fold change $\geq 1$; $p$-value $<0.05)$ among nonstressed and stressed $\left(2 \mathrm{mM} \mathrm{H}_{2} \mathrm{O}_{2}\right)$ cells in the absence or presence of melatonin $(5 \mu \mathrm{M})(\mathrm{Mel}$ vs. Control, MelH vs. $\mathrm{H})$. Percentages of enrichment are calculated as the ratio of the number of up- or downregulated genes in relation to the total genes involved in each molecular function in S. cerevisiae.

\begin{tabular}{|c|c|c|}
\hline GO Term Molecular Function ( $p$-Value) & $\%$ Enrichment & Gene Names \\
\hline \multicolumn{3}{|r|}{$\begin{array}{c}\text { Mel vs. Control } \\
\text { Upregulated (227 genes) }\end{array}$} \\
\hline $\begin{array}{c}\text { Transporter activity }(0.00174) \\
\text { Trasmembrane transporter activity }(0.01011)\end{array}$ & 7.21 & $\begin{array}{c}\text { OPT2, MEP1, SWH1, VMA11, YHK8, AGP1, COX5B, FET4, } \\
\text { AZR1, LAM5, FET3, PTR2, VMA3, HES1, GAP1, OPT1, } \\
\text { FCY21, MPC3, VPS73, STE6, CCC2, YMR279C, AAC3, } \\
\text { MAL31, DIP5, COX1, MUP3, HSP30, DUR3 }\end{array}$ \\
\hline Oxireductase activity (0.01995) & 6.96 & $\begin{array}{c}\text { YGL039W, HEM14, CUP1-2, COX1, SUR2, MDH2, GPD2, } \\
\text { RNR3, HEM13, TSA2, CUP1-1, FRD1, AAD10, EUG1, } \\
\text { MPO1, DLD3, HMG2, FET3, YJR149W, YGL185C, GLT1, } \\
\text { TDH3, COX5B, SHH4 }\end{array}$ \\
\hline L-serine ammonia-lyase activity $(0.02)$ & 75.00 & YIL168W, CHA1, YIL167W \\
\hline Structural constituent of cell wall (0.053) & 16.28 & TIR4, TIR1, SED1, PIR5, DAN1, YBR067C, DAN4 \\
\hline \multicolumn{3}{|r|}{ Downregulated (422 genes) } \\
\hline Ubiquinol-cytochrome-c-reductase activity $\left(2.11 \times 10^{-5}\right)$ & 77.78 & $\begin{array}{l}\text { COR1, QCR10, QCR8, QCR2, QCR9, QCR6, YEL024W } \\
\text { COX8, COX12, CYT1, QCR9, QCR6, COX4, CYB5, }\end{array}$ \\
\hline Inorganic molecular entity transmembrane transporter $(0.09017)$ & 11.72 & 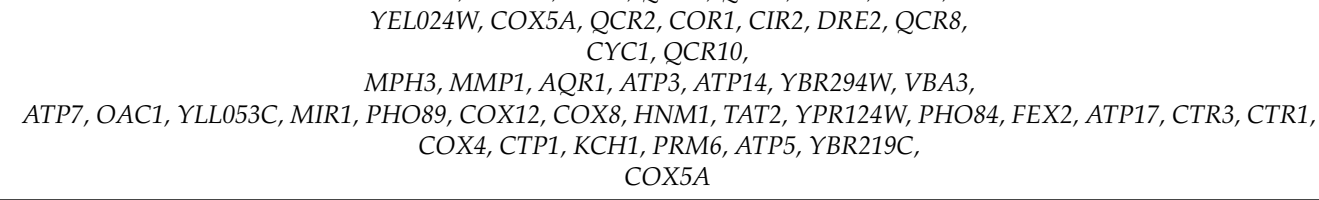 \\
\hline \multicolumn{3}{|r|}{$\begin{array}{c}\text { MelH vs. } \mathrm{H} \\
\text { Upregulated (498 genes) }\end{array}$} \\
\hline Oxireductase activity $\left(2.24 \times 10^{-6}\right)$ & 15.74 & $\begin{array}{c}\text { GDH3, COX8, QCR9, AYR1, ALD3, SDH4, COX5A, GLT1, } \\
\text { POX1, COX1, CUP1-2, HYR1, YKL071W, CUP1-1, MPD1, } \\
\text { TRX2, CYC1, GPX1, HOM6, FRE6, COX6, DLD3, TRX1, } \\
\text { COX3, MXR1, YKL107W, FRE3, COX7, COQ11, GTO1, } \\
\text { CTT1, TSC13, GIS1, CIR1, YPR127W, YCR102C, DOT5, } \\
\text { TPA1, GAL80, SER33, SUR2, SRX1, PRM4, HBN1, COX2, } \\
\text { QCR7, AAD10, FDH1, ETR1, GRX2, GRX1, EUG1, HFD1, } \\
\text { YJR096W }\end{array}$ \\
\hline Electron transfer activity $(0.00877)$ & 24.56 & $\begin{array}{l}\text { CIR1, GRX2, GRX1, COX7, COX8, QCR9, CYC7, PRM4, } \\
\text { COX6, COX5A, QCR7, COX2, COX3, COX1 }\end{array}$ \\
\hline $\begin{array}{l}\text { Antioxidant activity }(0.01019) \\
\text { Cytochrome-c oxidase activity }(0.02878)\end{array}$ & $\begin{array}{l}32.26 \\
41.18\end{array}$ & $\begin{array}{c}\text { CUP1-2, DOT5, HYR1, GRX2, CUP1-1, GRX1, GPX1, SRX1, GTO1, CTT1 } \\
\text { COX1, COX3, COX7, COX2, COX5A, COX6, COX8 }\end{array}$ \\
\hline Oxidoreductase activity acting on a sulfur group of donors ( 0.08819$)$ & 25.64 & $\begin{array}{l}\text { TRX1, GTO1, SRX1, PRM4, EUG1, GRX2, MPD1, TRX2, } \\
\text { GRX1, MXR1 }\end{array}$ \\
\hline \multicolumn{3}{|r|}{ Downregulated (277 genes) } \\
\hline Helicase activity $(0.0165)$ & 14.16 & $\begin{array}{c}\text { YRF1-6, YRF1-7, DBP1, ARP5, YRF1-5, YHL050C, MSS116, MPH1, DBP7, YLL067C, YEL077C, YRF1-8, DHH1, SNF2, } \\
\text { DBP3, YKU80 }\end{array}$ \\
\hline
\end{tabular}


In the presence of melatonin (Mel vs. Control), the oxidation-reduction process and the responses to abiotic stimuli and chemicals were the biological processes that were most significantly represented among the upregulated genes, followed by the response to decreased oxygen levels, which showed the highest enrichment (50\%), including 4 upregulated genes (YLR256W, FRD1, MGA2, UPC2) (Figure 2A and Dataset S13). Additionally, molecular functions related to transport activity and transmembrane transport were significantly overexpressed in the presence of melatonin, with 29 genes upregulated being found in this category (Table 2). Several pathways related to metabolism, especially that of carbohydrates (sucrose and TCA cycle) and sphingolipids, were also enriched (Figure 2C). In the case of downregulated genes, the most affected categories were related to mitochondrial electron transport and oxidative phosphorylation, with $50 \%$ of the cytochrome complex being downregulated, mostly represented by genes associated with complex III (80\% enriched) and cytochrome c reductase activity therein (Figure 2, Table 2). Moreover, categories related to ribosome biogenesis and the structures in which it takes place (preribosomes and nucleolus) were also highly enriched among the downregulated genes, together with categories related to RNA processing (Table 2, Figure 2).

Categories related to mitochondria were also highly enriched in the MelH vs. h comparison, as observed in the Mel vs. Control comparison; however, in this case, these categories were enriched in upregulated genes, such as complex IV and associated cytochrome c oxidase activity, which was the most enriched component (40\%), resulting in $32 \%$ enrichment of the cytochrome complex (Figure 2, Table 2). Categories related to antioxidant function and detoxification were also significantly overrepresented (Figure 2A, Table 2). The downregulated genes were enriched mainly in categories related to gene transcription, reproduction, and the regulation of these processes (Table 2, Figure 2).

Some of the GO categories and genes regulated by melatonin with or without stress will be discussed in more detail in the following sections. In the case of higher concentrations of melatonin (25MelH vs. MelH), although different gene expression profiles were observed, no significant differences were detected in the GO enrichment analysis.

\subsection{Effect of Melatonin on Transport and Membrane Composition}

Our transcriptomic study showed that the melatonin-upregulated genes were involved in transmembrane transporter activity in nonstressed cells, including transporters of ions [HSP30 (also upregulated by melatonin in stressed cells), CCC2, VMA3, YHK8, FET3, FET4, VMA11], amino acids (DIP5, GAP1, AGP1, MUP3), oligopeptides (OPT1, OPT2, PTR2) and urea (DUR3), among others (Table 2). Moreover, pathways related to lipid metabolism and peroxisomes were clearly altered in the presence of melatonin in both nonstressed and stressed cells. The melatonin-upregulated genes were involved in fatty acid (FA) elongation (13\% and 38\% enrichment in nonstressed and stressed cells, respectively) and the biosynthesis of unsaturated fatty acids (UFAs) (10\% and 30\%) and sphingolipids (21\% and 7\%, Figure 2) (SUR2, independent of the presence of oxidative stress, and LAC1 and ISC1 in nonstressed cells) (Table S2). Genes related to peroxisome and $\beta$-oxidation were also affected (13\%, $15 \%$ ) by melatonin and were both up- and downregulated.

In vertebrates, several of the functions of melatonin are mediated by its membrane receptors [43], but others are receptor-independent, such as antioxidant activity, for which melatonin is required to penetrate the cell and enter intracellular compartments [44]. In humans, melatonin is suggested to cross membranes by passive diffusion and through transporters of glucose [45] or oligopeptides [46,47]. Moreover, as the membrane is the first barrier that separates the cell from the environment, it is one of the main targets of oxidative stress, which alters its lipidic composition. Yeast cells can sense oxidative stress and change their membrane composition to achieve tolerance against stress, and this response varies among yeast strains and species [36]. Indeed, the diversity in the membrane composition in different yeast species and strains seems to lead to different levels of tolerance against oxidative stress [36]. Moreover, melatonin modulates the FA composition and peroxisome proliferation in stressed and nonstressed cells, suggesting that it could influence the lipidic composition of cell membranes to achieve tolerance to oxidative stress [15]. 
Therefore, because melatonin modulated the expression of several genes involved in membrane transport and lipid metabolism, it was of interest to determine whether yeast cells are able to incorporate exogenous melatonin, whether this incorporation is altered by oxidative stress and whether the presence of melatonin in the medium affects the yeast membrane composition, either to prepare the cell to tolerate oxidative stress or to deploy a response that could lead to better tolerance against this stress.

\subsubsection{Intracellular Melatonin}

To evaluate whether the QA23 strain was able to incorporate exogenous melatonin into the cell, intracellular melatonin was quantified under our four different conditions (Control, Mel, $\mathrm{h}$ and $\mathrm{MelH}$ ) (Figure 3). Intracellular melatonin levels significantly increased when the cells were grown with melatonin supplementation independent of oxidative stress, indicating that $S$. cerevisiae (QA23 strain) was able to take up exogenous melatonin at nanomolar concentrations. Similar results have been previously reported in yeast [14] and mammals [48,49]. Our results also showed that the highest levels were reached in stressed cells that were previously grown in the presence of melatonin (Figure 3). The higher melatonin levels in stressed cells may be due to the changes induced by $\mathrm{H}_{2} \mathrm{O}_{2}$ in both plasma membrane permeability and the gradient thereof, which might promote changes in cellular transport [50] favoring the entry of melatonin into the cell. Another possible route through which melatonin may enter the cell is potentially through some membrane transporters, such as those for urea or polyamines (DUR3) (as they present a similar structure to melatonin), the oligopeptide transporter OPT1, or the maltose permease MAL31, the last two of which were upregulated by melatonin in presence and absence of oxidative stress (Figure 1E). Huo et al. [46] recently described the possible involvement of PEPT1/2 oligopeptide transporters in the uptake of melatonin in mammalian cells, and a new line of evidence has shown that glucose transporters are linked to melatonin uptake in human cells $[45,47]$. Indeed, our results showed that some genes encoding carbohydrate and carbon source transporters were upregulated by the presence of melatonin in stressed cells (HXT5, HXT6, HUT1, JEN1, Dataset S4), which could also be related to melatonin internalization. Nevertheless, further studies should be performed to elucidate the possible role of these transporters in melatonin uptake by yeast cells.

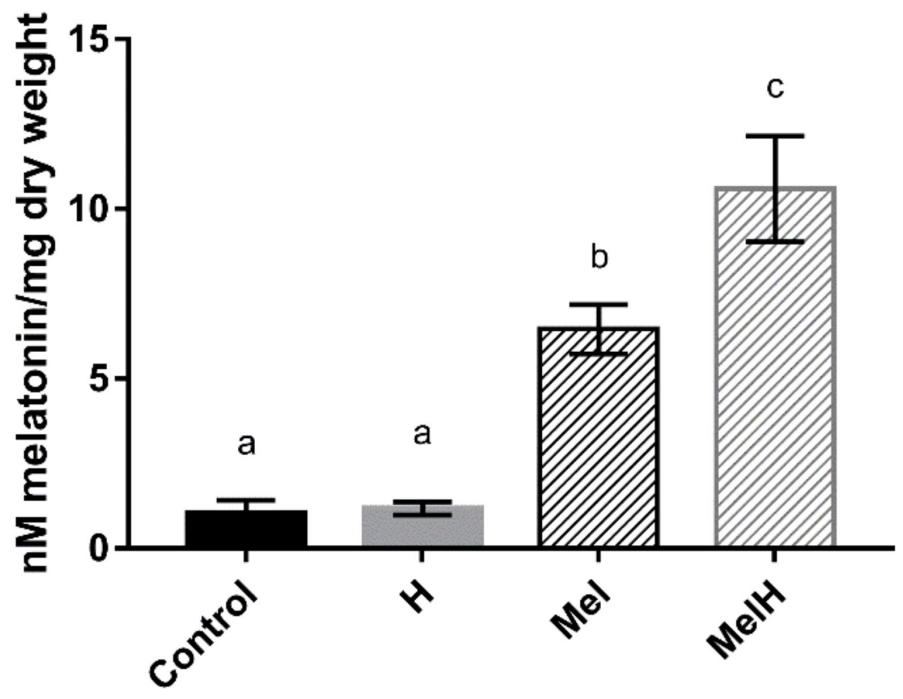

Figure 3. Intracellular melatonin quantification in cells untreated and treated with $5 \mu \mathrm{M}$ of exogenous melatonin, before (Control and $\mathrm{Mel})$ and after $(\mathrm{H}$ and $\mathrm{MelH})$ being exposed to oxidative stress with $2 \mathrm{mM}$ of $\mathrm{H}_{2} \mathrm{O}_{2}$. Error bars represent standard deviation, letters show statistical differences with $p$-value $<0.05$. 


\subsubsection{Physiological Changes in the Lipid Composition}

To test whether the abovementioned transcriptomic modifications resulted in changes in the cell lipid composition, we measured the sterol and PL contents of the yeast cells under the four different conditions (Control, Mel, MelH and H, Figure 4). In a previous study, we measured the changes in the fatty acid composition under these four conditions [15].
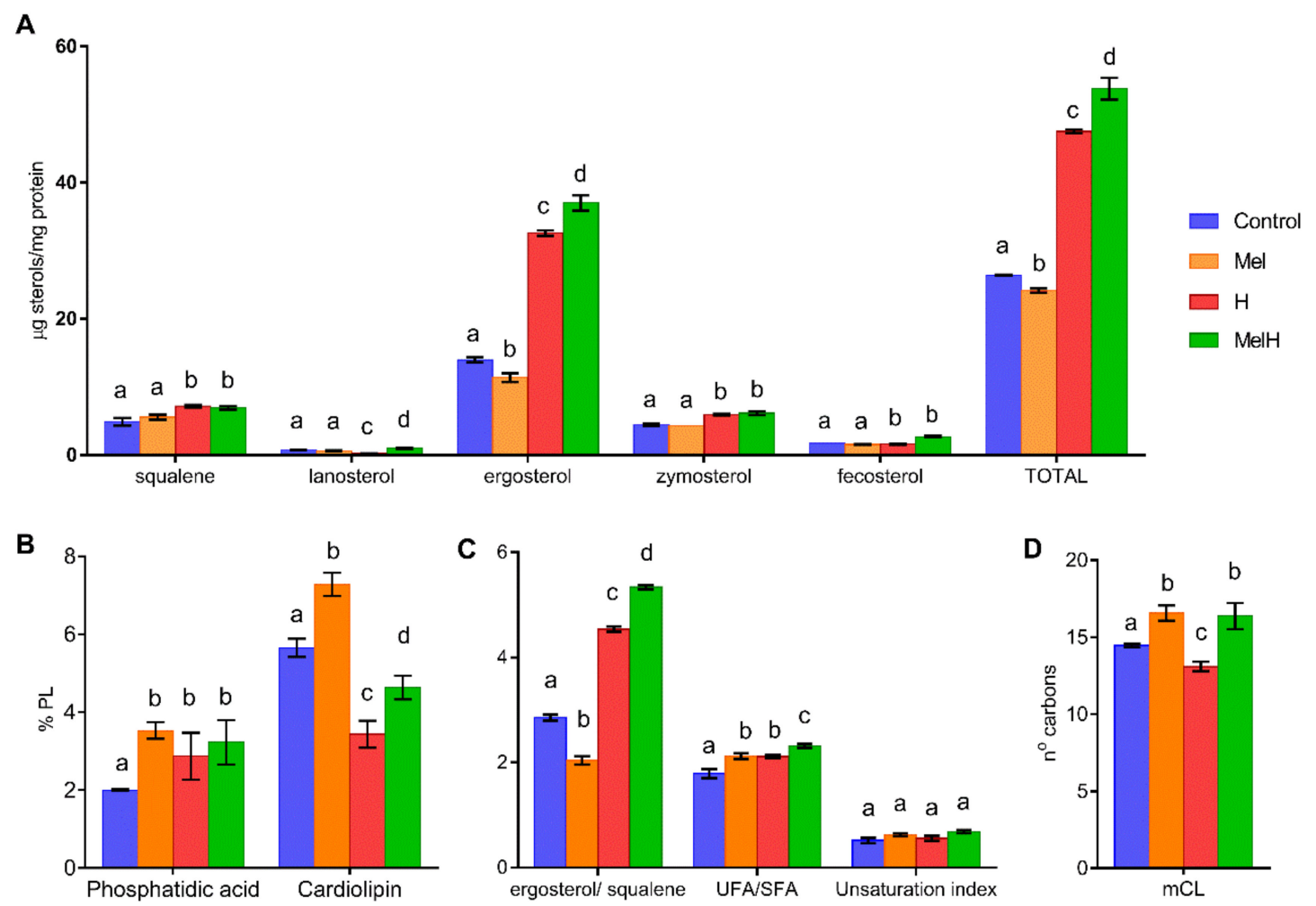

Figure 4. Lipid composition of nonstressed and stressed yeast cells with $2 \mathrm{mM}$ of $\mathrm{H}_{2} \mathrm{O}_{2}$, grown with and without $5 \mu \mathrm{M}$ of melatonin (Control, Mel, H, MelH). (A) Sterols. (B) Phospholipids. (C) UFA/SFA ratio (from Vázquez et al. [15]) and unsaturation index defined as follows: [(\% C16:1 + \% C18:1) + $2(\% \mathrm{C} 18: 2)+3$ (\% C18:3)]/100. (D) Medium-chain-length of FA (mCL, from Vázquez et al. [15]). Letters indicate significant differences between lipid concentrations $(p$-value $<0.05)$.

In nonstressed cells, melatonin supplementation resulted in lower total sterol levels than in the control condition, primarily because of a lower ergosterol content (Figure 4A), leading to a lower ergosterol/squalene ratio (Figure $4 \mathrm{C}$ ). The opposite situation was found under oxidative stress, with higher levels of total sterols, mainly due to increased ergosterol, leading to a higher ergosterol/squalene ratio (Figure $4 \mathrm{~A}, \mathrm{C}$ ). A study that compared the membrane composition of different yeast strains showed that the most $\mathrm{H}_{2} \mathrm{O}_{2}$-tolerant strains exhibited a low sterol content before stress and an increased ergosterol/squalene ratio after oxidative stress [36], behavior that we observe with melatonin supplementation in the present study. Moreover, an increase in total sterols has been related to higher tolerance to $\mathrm{H}_{2} \mathrm{O}_{2}$ and other stress conditions [51]. This suggests that one of the mechanisms by which melatonin confers resistance against $\mathrm{H}_{2} \mathrm{O}_{2}$ could be alteration of the ergosterol composition. The observed physiological behavior seems opposite to the pattern of the regulation of genes involved in sterol biosynthesis and transport, as these genes were upregulated in nonstressed cells (ARE1, DAN1, IZH4, FHN1, HES1, UPC2) and downregulated in stressed cells (ARE2, ERG11, SWHI1, UPC2). This could be explained by the regulatory role of $U p c 2 p$, a transcription factor that activates genes involved in sterol biosynthesis and transport and anaerobic genes and is activated under sterol depletion and anaerobic conditions (reviewed by Joshua and Höfken [52]). Therefore, its targets 
would be downregulated in the presence of high sterol concentrations (in stressed cells, melatonin downregulated ERG11) and upregulated in the presence of low sterol concentrations (in non-stressed cells, melatonin upregulated FHN1, ARE1, HES1 and particularly DAN1, a cell wall mannoprotein and sterol transporter). Thus, it seems that the increase in the ergosterol content in the presence of melatonin could be produced during the first hour of oxidative stress, and genetic regulation could be a response to the sterol concentration. This increase in the ergosterol content could be driven by either posttranscriptional enzyme activation or higher oxygen availability, which is required for ergosterol biosynthesis [53].

On the other hand, the changes in FAs produced by melatonin were independent of stress, with higher oleic and palmitoleic acid contents [15] leading to a higher total FA level, a higher UFA/SFA ratio and an increased percentage of medium chain length (mCL) FAs in Mel and MelH conditions (Figure 4C,D). This increase was correlated with the induction of the genes involved in the FA synthesis and elongation pathways (TES1 in the absence of oxidative stress and TSC13, PHS1, ETR1 in the presence of oxidative stress), among which the thioesterase gene TES1, which is involved in the last step of the synthesis of several UFAs (such as oleic acid), and the TSC13 and PHS1 genes, which are involved in long-chain FA elongation, were the most affected by melatonin treatment. Moreover, high UFA/SFA ratios have been related to higher tolerance to $\mathrm{H}_{2} \mathrm{O}_{2}$ [54]. In fact, yeast strains with higher $\mathrm{H}_{2} \mathrm{O}_{2}$ tolerance showed higher UFA/SFA ratios before and after stress [36], with increases in palmitoleic and oleic acid levels being observed after stress, as observed under melatonin treatment. These results suggest that melatonin changes in the membrane FA composition improve the tolerance to oxidative stress. Genes related to $\beta$-oxidation and peroxisomes were mostly upregulated by melatonin under oxidative stress in this study (POX1, PXA1, PEX19), which suggests that melatonin could increase the $\beta$-oxidation of FAs inside peroxisomes. These results are consistent with the higher FA content observed under melatonin treatment, but they are not consistent with the increased peroxisome proliferation observed in nonstressed cells and the decreased peroxisome proliferation observed in stressed cells [15].

Finally, the only observed changes in the PL content were related to phosphatidic acid (PA) and cardiolipin (CL). Melatonin only increased PA levels in the absence of stress, and although the CL level decreased in the presence of oxidative stress, it was higher under both conditions involving melatonin supplementation (Figure 4B). Vázquez et al. [36] observed that all investigated strains showed a decrease in CL after stress exposure, but the strains that were most tolerant to $\mathrm{H}_{2} \mathrm{O}_{2}$ displayed higher $\mathrm{CL}$ values, as observed under melatonin treatment. In humans, melatonin prevents the peroxidation of cardiolipin to protect mitochondria from damage provoked by aging [22]. However, these results were not correlated with gene expression data, which revealed that in stressed cells, melatonin upregulated some of the genes involved in the biosynthesis of phosphatidylcholine (CPT1) and sphingolipids (SUR2), which are related to stress tolerance.

\subsection{Response to Oxidative Stress}

Our results showed that $32 \%$ of the genes involved in antioxidant activity were upregulated by melatonin in stressed cells (Table 2), including glutaredoxins (GRX1, GRX2), sulfiredoxin (SRX1) and four peroxidases (DOT5, HYR1, GPX1 and CTT1), together with other genes with oxidoreductase activity, such as thioredoxins (TRX1, TRX2) and methionine-S-sulfoxide reductase (MXR1) (Table 2). These results were consistent with our previous studies [16], in which we observed that genes such as GPX1, GRX2, TRX2 and CTT1 were also induced by melatonin in S. cerevisiae stressed cells. Instead, in non-stressed cells, melatonin upregulated the cytoplasmic thioredoxin peroxidase TSA2 but downregulated its paralog TSA1 and the thioredoxin TRX2, mitochondrial superoxide dismutase SOD2 and glutathione peroxidase GPX2 genes (Dataset S1). Therefore, melatonin seems to downregulate the antioxidant response in the absence of oxidative stress. Other studies point in the same direction, as they have also shown that the expression of GPX1, SOD2, GPX3 and CTA1 was downregulated in the presence of melatonin $[14,16]$. 
To confirm our transcriptomic data, some of the genes related to stress tolerance showing higher expression ratios in MelH vs. h condition were verified by qPCR analysis using the same conditions as in the transcriptomic assay: SRX1, which encodes a sulfiredoxin that contributes to protection against oxidative stress [55,56]; $A D Y 2$, which encodes a carboxylic acid transporter of the plasma membrane implicated in acetic acid tolerance [57]; and $M G A 1$, a stress-responsive gene that regulates Cis1p (explained in Section 3.6). In spite of the results of the Mel vs. Control comparison, which were nonsignificant, the MelH vs. h results showed tendencies that supported the results of the microarray analysis (Table S4).

Moreover, independent of the application of stress, melatonin upregulated the copper transporter CCC2 and both metallothioneins (CUP1-1 and CUP1-2), which have antioxidant and superoxide dismutase activity, and are involved in the detoxification of metal ions and removal of superoxide radicals, and downregulated the copper transporters CTR1 and CTR3 (the latter only in nonstressed cells) (Figure 1, Table 2). FET3, which contributes to resistance to copper toxicity, was upregulated by melatonin in the absence of oxidative stress (Table 2, Dataset S1). In a previous study, we observed that melatonin upregulated other metal-related antioxidants, such as SOD1 [16]. Therefore, our results seem to indicate that melatonin activates a response against the toxic effects of metal exposure in S. cerevisiae, as reported in human cells $[3,58]$, even without the presence of metals, as a mechanism for better enduring further stresses.

\subsection{Effect of Melatonin on the Mitochondria}

Many of the genes regulated by melatonin were located in mitochondria (89 genes in Mel vs. Control and 107 in MelH vs. H), mainly in the respiratory chain complexes and mitochondrial envelope (Figure 2, Table 3); these results suggested that the mitochondria could be the biological target of melatonin, as observed in humans [59]. However, the effects of melatonin on mitochondrial genes were opposite in stressed and nonstressed conditions, since melatonin mainly downregulated mitochondrial genes in nonstressed cells but upregulated these genes in stressed cells (Table 3).

In non-stressed cells, most of the repressed genes were related to the ETC, particularly to cytochrome c reductase [complex III, including two catalytic (RIP1, CYT1) and six additional subunits], as well as complexes IV, V and other ETC-related elements, such as NADH dehydrogenase, a cytochrome $c$ isoform and enzymes involved in the process of obtaining the heme groups of ETC complexes. Melatonin also downregulated most of the genes related to other mitochondrial functions, such as protection, morphology, transport, mitoribosome and intergenomic signaling between the nucleus and mitochondria. However, some genes were also upregulated, such as SHH4 of complex II of the ETC, a respiratory supercomplex factor, and genes involved in the TCA cycle and heme synthesis (Table 3). On the other hand, in stressed cells, the induced mitochondrial genes were mainly related to cytochrome c oxidase (complex IV), including not only genes that encode the central units (COX1-3) but also genes related to assembly (such as ATP20), stability, regulation or enzyme activity. Melatonin also upregulated genes associated with other ETC complexes as well as a respiratory supercomplex factor or a cytochrome $\mathrm{c}$ isoform and genes related to mitochondrial functions such as protection, morphology, mitoribosomes, intergenomic signaling or the TCA cycle. However, in the transport, translation and metabolism categories, there were both up- and downregulated genes. 
Table 3. List of mitochondrial genes regulated by melatonin in nonstressed cells (Mel vs. Control) and stressed cells (MelH vs. H). The fold change and $p$-values are provided in Datasets S1 and S4. They are classified into different categories, and the genes that were upregulated and downregulated in each condition are listed.

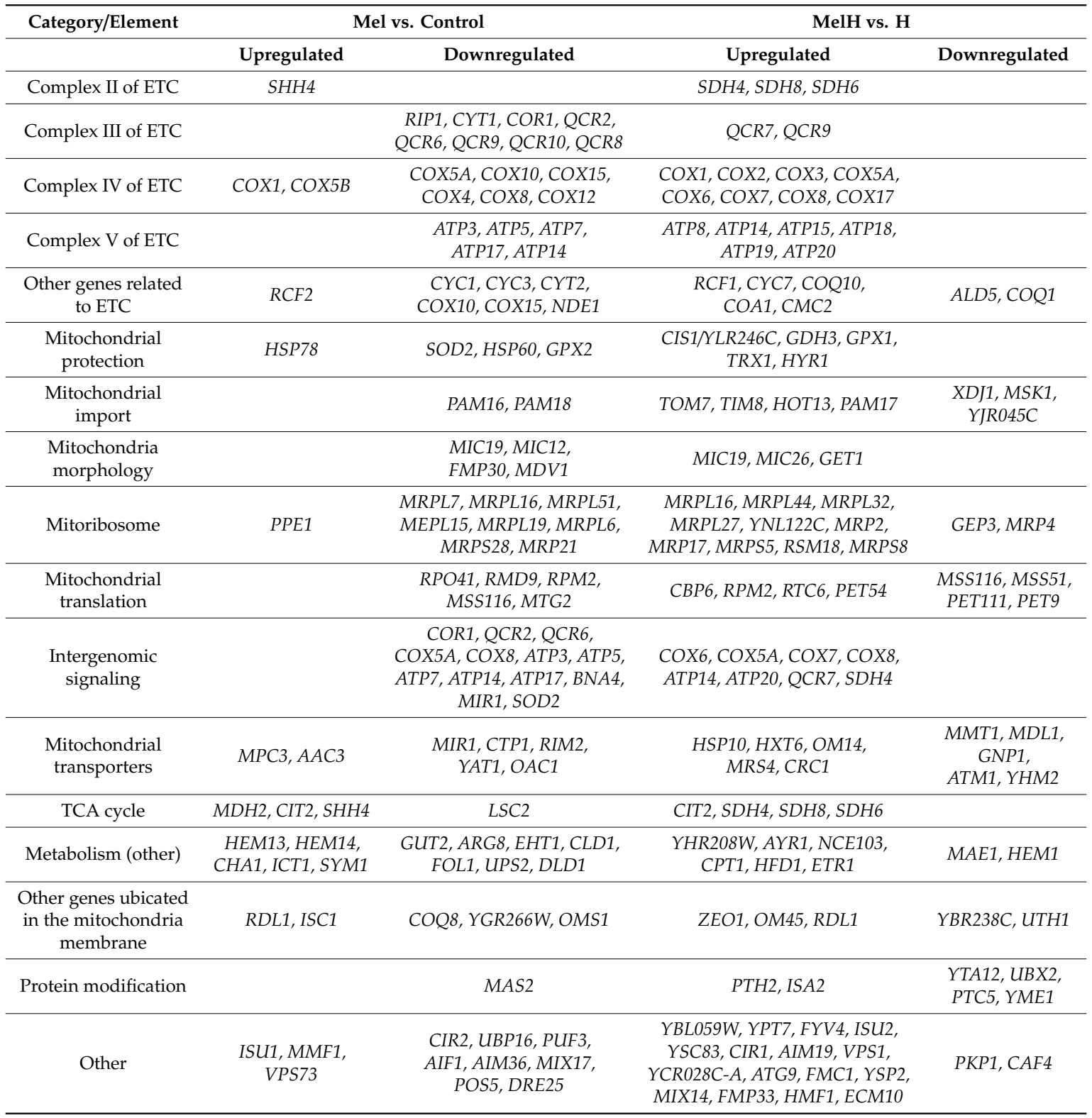

\subsubsection{Gene Validation}

As mitochondria were the most enriched component, to confirm our transcriptomic data, the expression of some mitochondrion-related genes showing higher expression ratios in the MelH vs. $\mathrm{h}$ comparison were verified through qPCR analysis. We chose genes related to different mitochondrial functions, such as genes involved in the respiratory chain (COX2, SDH6, ATP20), structure (ATP20), mitochondria protection (GDH3, CIS1) and transport (MMT1) (Figure 5).

Gene expression was analyzed at the same sampling points used in the microarray assays and at different growth times under the four conditions (Control, $\mathrm{Mel}, \mathrm{H}, \mathrm{MelH})$, and the results are shown in Figure 5. Most of the selected genes were upregulated either by entry into the stationary phase or by the response to oxidative stress exposure (which inhibited cell growth for $12 \mathrm{~h}$, Figure 5A), following a general environmental stress response profile [60]. In nonstressed cells (Control condition), 
almost no changes in the expression of these genes were observed during the exponential phase (1 and $4 \mathrm{~h}$ ) (Figure 5A,B), and only some of the genes were slightly downregulated (SDH6, CIS1) or upregulated (GDH3). However, the expression of all the genes (except MMT1) increased significantly in the stationary phase (12 and $24 \mathrm{~h}$ ) (Figure 5A,B). Exposure to oxidative stress upregulated the expression of all genes, and these changes were significant for some of them at $1 \mathrm{~h}$ and for all the rest, except for GDH3, at $4 \mathrm{~h}$ (Table S3); their expression then decreased during the exponential phase $(24 \mathrm{~h})$, reaching the same levels observed before the stress in some cases, and significantly increased at the stationary phase (36 h) (Figure 5B). An exception was observed for MMT1, whose expression decreased in the stationary phase, as observed in the control condition.
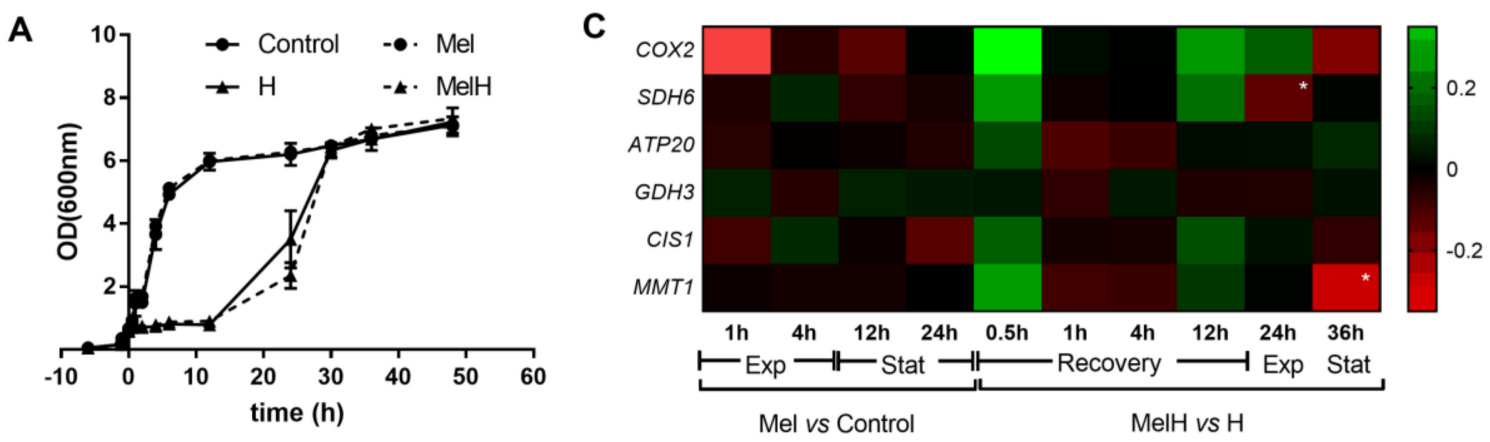

B

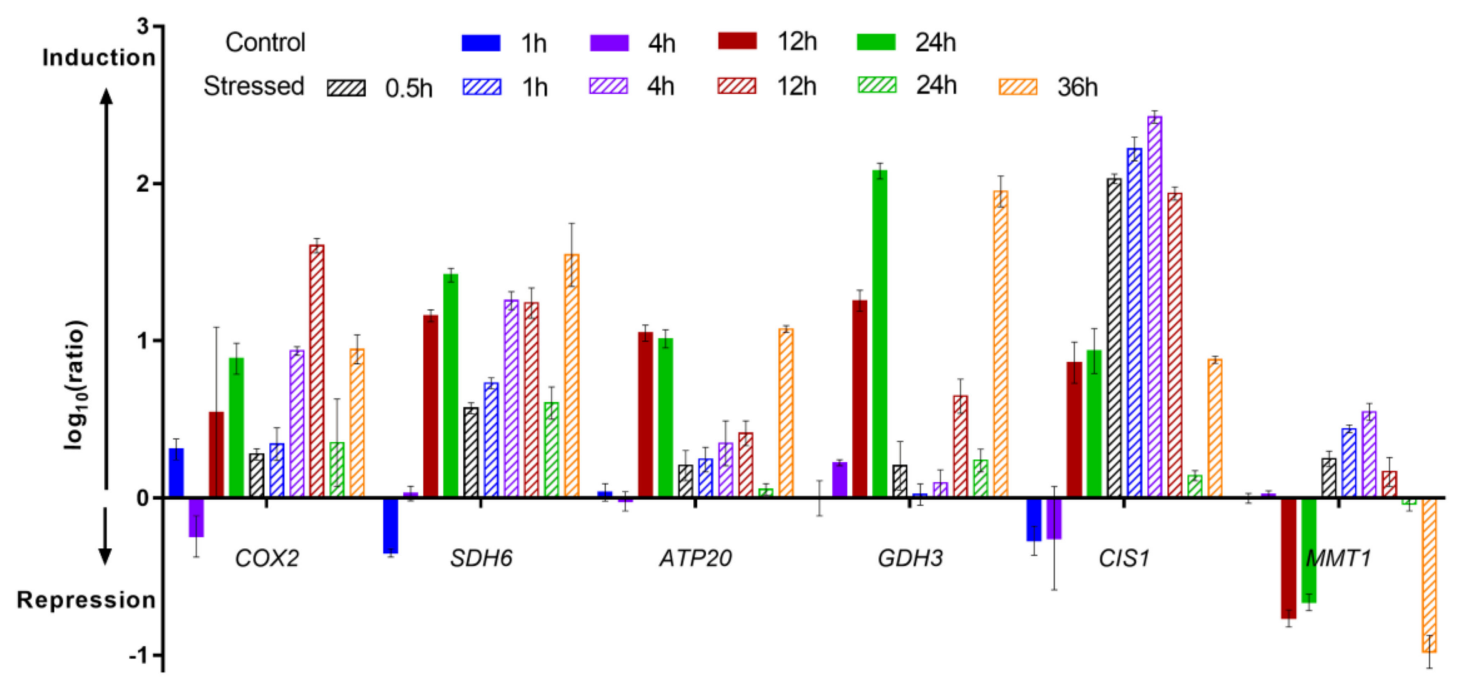

Figure 5. Expression of six selected genes over a time course. (A) Kinetics of yeast growth according to $\mathrm{OD}_{600 \mathrm{~nm}}$ values. The cells were incubated with or without melatonin $(5 \mu \mathrm{M})$ for $6 \mathrm{~h}$, and two conditions ( $\mathrm{Mel}, \mathrm{MelH})$ were subjected to $2 \mathrm{mM} \mathrm{H}_{2} \mathrm{O}_{2}$ treatment $(0 \mathrm{~h})$. (B) Expression of each gene of interest at different time points in the nonstressed and stressed conditions (Control, H), expressed as $\log _{10}$ (ratio). The ratio represents the $2^{-\Delta \Delta C t}$ value corrected to the $2^{-\Delta \Delta C t}$ value of the Control at $0 \mathrm{~h}$. (C) Heat map of the effect of melatonin on the expression of the six genes during the time course analysis in nonstressed and stressed cells. The color corresponds to the $\log _{10}$ of the ratio. The ratio represents the $2^{-\Delta \Delta C t}$ value for the condition with melatonin corrected to the $2^{-\Delta \Delta C t}$ value for the condition without melatonin. Genes are presented in rows, and the time points under both conditions are presented in columns. Exp, exponential phase; stat, stationary phase. High-intensity colors refer to values $>0.35$ (green) or $<-0.35$ (red) * significance level of $<0.05$. Error bars represent the standard deviation, and the statistical analysis of B and C is presented in Table S3. 
The effect of melatonin on the expression of these genes in stressed and nonstressed cells is presented in Figure 5C. In nonstressed cells (Mel vs. Control), melatonin slightly decreased the expression of most of the genes in the early exponential phase $(1 \mathrm{~h})$, but practically no changes were observed in the exponential and stationary phases (Figure 5C). In stressed cells (MelH vs. H), melatonin induced most of the genes immediately after stress was applied $(0.5 \mathrm{~h})$, indicating an additive effect to the stress, after which the expression of most genes was slightly lower in MelH than in $\mathrm{h}$ conditions (1-4 h), followed by an increase just before entering the exponential phase (12 h). Thereafter, no important changes were observed in the exponential and stationary phases, except in SDH6 and MMT1, respectively, whose expression was lower under MelH conditions (Figure 5C). Overall, the qPCR results supported those of the microarray analysis (Figure 5C, Table S4).

\subsubsection{Physiological Effect of Melatonin in Mitochondria}

To determine whether the high impact of melatonin on mitochondrial gene expression revealed physiological effects such as an increase in the concentration or activity of mitochondria, we analyzed the number of mitochondria per cell using MitoTracker Green, a dye that accumulates in the active mitochondria of living cells, regardless of the mitochondrial membrane potential. When the cells were subjected to oxidative stress $\left(2 \mathrm{mM} \mathrm{H}_{2} \mathrm{O}_{2}\right)$ for $1 \mathrm{~h}$, fluorescence in the cells increased, indicating a greater number of mitochondria per cell. This increase was greatest, and the difference was statistically significant in the presence of a high concentration of $\mathrm{H}_{2} \mathrm{O}_{2}(5 \mathrm{mM})$ (Figure 6). Moreover, in nonstressed cells or stressed cells in the presence of a low concentration of the oxidative compound $(2 \mathrm{mM})$, the presence of melatonin increased the number of mitochondria, which became even higher when the melatonin concentration was increased $(50 \mu \mathrm{M})$. However, when the stress was increased $(5 \mathrm{mM})$, the presence of melatonin did not affect the number of mitochondria per cell, which was already quite high due to the intensification of oxidative stress (Figure 6). These tendencies were also observed in the presence of $10 \mathrm{mM} \mathrm{H}_{2} \mathrm{O}_{2}$ (data not shown).

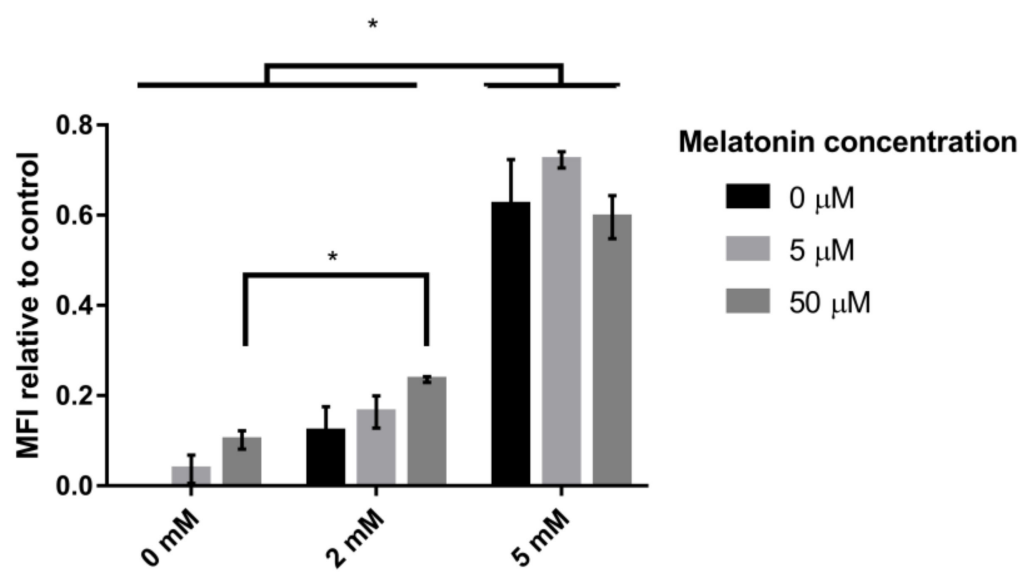

Figure 6. Effect of $\mathrm{H}_{2} \mathrm{O}_{2}$ and melatonin on the number of mitochondria per cell. The values are expressed as the mean fluorescence intensity (MFI) of the different conditions compared to the control. The cells were incubated with different melatonin concentrations $(0 \mu \mathrm{M}, 5 \mu \mathrm{M}$ and $50 \mu \mathrm{M})$ and then subjected to treatment with different $\mathrm{H}_{2} \mathrm{O}_{2}$ concentrations $(0 \mathrm{mM}, 2 \mathrm{mM}$ and $5 \mathrm{mM})$. Error bars represent the standard deviation, and * indicates statistically significant differences between media $(p<0.05)$.

The observation that melatonin affects complexes in different ways depending on the presence or absence of oxidative stress is supported by the validation analysis of two genes necessary for the growth during respiratory metabolism, COX2 and ATP20: melatonin upregulated these genes after oxidative stress and downregulated them in non-stressed cells. COX2 encodes a central subunit of Complex IV necessary to assemble a functional complex, and ATP20 encodes a subunit of Complex V 
that produces a functional association with Complex IV, which is essential to achieve maximum levels of Complex IV activity [61].

This, together with the increase in complex IV activity observed by Zampol and Barros [24], shows similar behavior to that of melatonin in human cells, in which melatonin increases the activity and gene expression of Complex IV [62,63]. In mammals, one of the main roles of melatonin is the maintenance of the respiratory chain flux, mainly by increasing the activity of Complexes I and IV $[64,65]$. Since S. cerevisiae lacks Complex I, it seems that the action of melatonin could be focused on Complex IV, possibly due to the important role of Complex IV in ETC regulation. Defects in Complex IV increase ROS production, so this complex seems to be an indicator of the cell oxidative capacity and thus to be pivotal in ETC regulation [66-68]. On the other hand, Complex III was the most affected by melatonin in non-stressed cells, in which most of the genes related to this complex were repressed. In mammalian cells, despite the clear antioxidant function of melatonin, several works have reported that melatonin per se can act as a prooxidant to induce ROS generation in several cell lines [69-71], an effect that has also been suggested in yeast cells [16]. Recently, it was revealed that the ROS generation induced in mammalian cells by melatonin at micromolar concentrations occurs via Complex III [72]. Moreover, Hardeland [73] noted in a review that Complex III activity has been found to be unchanged or upregulated by melatonin in different studies in different cell types. However, in yeast, melatonin seems to repress the expression of this complex; therefore, the effect of melatonin in this complex must be further studied.

Melatonin differentially regulates the expression of genes involved in mitochondrial protection. $G D H 3$, which encodes a protein involved in the glutathione system and ROS reduction in the stationary phase, is upregulated in non-stressed cells and downregulated in stressed cells ( 1 and $12 \mathrm{~h}$ ) by melatonin. In contrast, melatonin downregulated the expression of CIS1 in nonstressed cells but upregulated its expression after stress exposure ( 0.5 and $12 \mathrm{~h}$ ) (Figure 5). Cis1p, a mitochondrial protein whose biological role is unknown in yeast, has been recently reported to participate in the mitochondrial import surveillance mechanism, alleviating protein import stress [74]. Mitochondrial import stress has been associated with an increase in the mitochondrial mass and with mitochondrial stress conditions, such as high levels of ROS [74]. Therefore, the observed induction of CIS1 in conditions that resulted in an increase in the mitochondrial content per cell $(\mathrm{H}$ and $\mathrm{MelH}$, Figures 5 and 6) supported the hypothesis that this induction could be a response to maintain active mitochondrial import and, thus, mitochondrial function. Moreover, CIS1 is induced by the transcription factor PDR3, which also mediates a multidrug resistance (MDR) response, and in our work, the conditions of stress and melatonin treatment (in stressed cells) also upregulated PDR1, another transcription factor related to MDR (reviewed in Kolaczkowska and Goffeau [75]). Therefore, one of the actions of melatonin could be the triggering of the MDR response.

Our results indicated that melatonin plays a very important role in mitochondria, suggesting that it could be the biological target of melatonin, as observed in humans [59], because in both organisms, mitochondria are the site of higher production of ROS/RNS [22] and therefore the site where the reported antioxidant effect of melatonin is most needed. Nevertheless, melatonin seems to play roles other than counteracting the effects of oxidative stress (as seen in mammalian cells [76]) because while the effect of melatonin is focused on the ETC, this stress mainly affects the mitoribosomes and the inner membrane (Datasets S11-S19), suggesting that the targets of melatonin in mitochondria could be different from those observed in association with oxidative stress. This is supported by the observation that melatonin affects different complexes and genes in different ways depending on the presence or absence of oxidative stress.

\subsection{Effect of Melatonin on Cell Signaling}

The transcription factors involved in the different conditions were determined using PheNetic, a web tool that uses publicly available interactomics data to create networks and reveal possible relevant regulators. An interaction network was created using all the genes that were found to be 
differentially expressed $(-1<\mathrm{FC}>1, p$-value $<0.05)$ in the Mel vs. Control and MelH vs. h comparisons to identify the relevant regulators of the effects of melatonin (Figure S1A,B). As melatonin seemed to have a great effect on mitochondria, another network was created using only the mitochondrial genes that were differentially expressed in these conditions (Figure 7A,B).
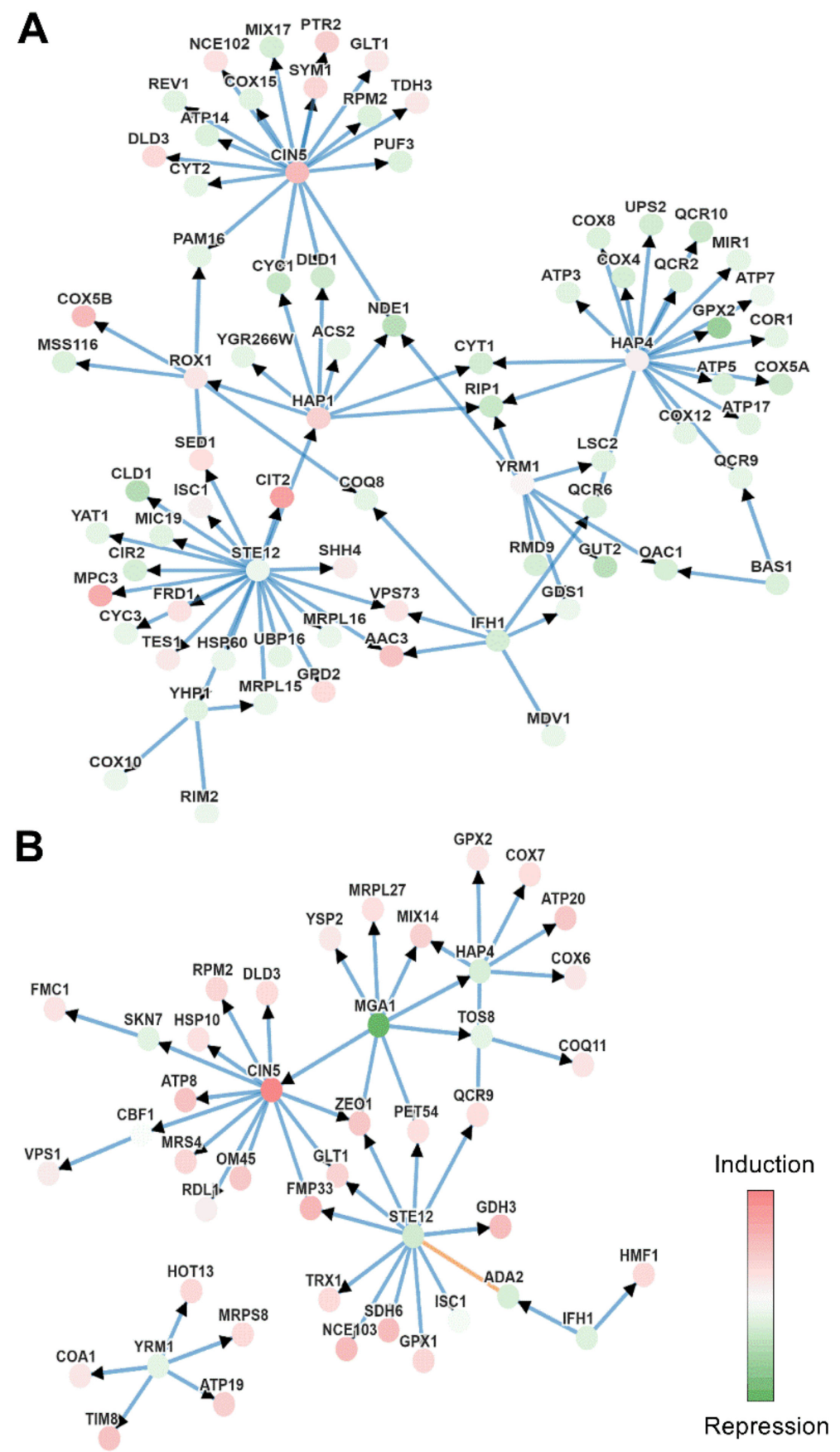

Figure 7. Genetic interactions given by Phenetics using mitochondrial genes with $-1<\mathrm{FC}<1$, $p$-value $<0.05$. Set of genes used in each comparation: (A) Mel vs. Control. (B) MelH vs. H. Nodes represent molecular entities, and the intensity of its color represents the level of differential expression, green being under-expression and red over-expression. The edges indicate the interaction between the genes (blue indicates protein-DNA and orange protein-protein), and the arrows the direction of the interaction. 
The analysis highlighted Cin $5 p$ and Ste12p as the central transcription factors among the genes regulated by melatonin in stressed and non-stressed cells (Figure S1). CIN5, which was upregulated by melatonin in all conditions, is a member of the Yap family and is upregulated after the application of an external stimulus such as oxidative or osmotic stress (reviewed in Rodrigues-Pousada et al. [77]). Cin5p induces genes upregulated by melatonin in stressed cells (such as SRX1, SET6 or HSP30) and in non-stressed cells (such as HSP42, ISF1, GSY1, PIG2, HSP30 or GAC1) [78-80]. Both CIN5 and ADY2, which were upregulated by melatonin in stressed cells in our study (Figure S1B, Table S4, Dataset S4), are known to be activated by Msn2/4p stress-responsive transcription factors [58,81]. This suggests that melatonin could increase the response to oxidative stress in stressed cells, indicating an additive effect to the stress, which supports the results of Section 3.4 regarding the response to oxidative stress.

Ste12p, Mga1p (a node in MelH vs. H, Figure S1B) and Gat3p (a node in Mel vs. Control, Figure S1A) regulate filamentation and activate genes related to pseudohyphal/invasive growth [82,83]. These transcription factors seemed to be downregulated by melatonin, which suggests that melatonin could modulate filamentous growth in S. cerevisiae, as reported for some aromatic alcohols (such as phenylethanol and tryptophol) $[84,85]$ produced (similarly to melatonin) through aromatic amino acid metabolism.

When we focused only on mitochondrial genes, the same transcription factors were identified together with some additional transcription factors, such as Hap4p and Yrm1p in both stressed and nonstressed cells and Hap1p and Rox1p only in the Mel vs. Control comparison (Figure 7). Hap1p, Hap4p and Rox1p are heme-dependent transcriptional regulators. In the presence of heme, the Hap2/3/4/5 complex (in which Hap4p provides the activation domain) and Hap1p activate and upregulate genes required for aerobic growth, and Hap1p is also responsible for activating Rox1p, a repressor of hypoxic-related genes.

Therefore, in low-oxygen conditions (hypoxic growth), Rox1p is not expressed, and hypoxia-related genes are upregulated (reviewed by Siso et al. [86]). In our study, melatonin downregulated genes related to aerobic conditions in non-stressed cells (mitochondrial or nonmitochondrial) that are targets of Hap1p (NDE1, CYC1 but also CIR2 and CLD1), Hap2/3/4/5 complex (COX5A, COX4 but also INH1) or both factors (CYT1, RIP1) (Figure 7, Dataset S1) [79,87].

Under the same conditions, melatonin also upregulated several hypoxia-related genes that are targets of Rox1p, including three of the most upregulated genes (DAN1, HEM13 and ANB1), several mitochondrial genes (COX5B, AAC3 or RCF2) and other nonmitochondrial genes with high fold-changes (FCs) (FET4, ARE1, GAC1, SUR2, FET3 and LAC1) (Figures 2 and 7C, Dataset S1) [79,80]. All of these results suggest that melatonin could activate a hypoxic response in yeast cells, despite the slight upregulation of the transcription factors HAP1, HAP4 and ROX1 (which was only significant for HAP1) (Dataset S1). Indeed, Hap1p is known to be regulated by its interaction with heme at the protein level but not at the transcriptional level (reviewed at Siso et al. [86]).

Other results obtained also supported the notion that melatonin could trigger a hypoxic response in nonstressed cells, such as the enrichment of the "response to decreased oxygen levels" among the upregulated genes in the Mel vs. Control comparison (Figure 2, Dataset S13). Among these genes, we found UPC2, a sterol regulatory element that controls the expression of an anaerobic sterol transport system. The regulation of sterol import is tightly connected to anaerobic conditions, as it is specific to anaerobic growth $[53,88]$. Under anaerobic conditions, Upc2p is upregulated and induces the expression of the DAN/TIR genes, a group of eight cell wall mannoproteins that are expressed under anaerobic conditions [89]. Indeed, our results showed the upregulation of four genes of this complex, DAN1, DAN4, TIR1 and TIR4, which are associated with the enriched "structural constituent of the cell wall" molecular function category (Table 2). DAN1, a well-known hypoxic-related gene, was the gene showing the highest FC in the Mel vs. Control comparison (Dataset S1). Some of our results agreed with those of Bendjiali et al. [90], which describes a response specific to hypoxia.

Indeed, it has been reported that hypoxia induces the formation of foci containing glycolytic enzymes, which increases the incorporation of carbon into pyruvate and oxaloacetate [91]. Recently, 
melatonin has been shown to bind a complex of glycolytic enzymes [17], and this binding would be related to yeast fermentative capacity [18]. Several glycolytic genes found in this complex, such as PYC2 and TDH3, were upregulated by melatonin in non-stressed cells (Figure 1B,E, Dataset S1). Therefore, it seems that melatonin could trigger a hypoxia-like response in non-stressed $S$. cerevisiae cells regulated by the Hap complex, which could increase their fermentation performance. Nevertheless, more studies are needed to examine this hypothesis.

\section{Conclusions}

This study is the first to reveal the yeast transcriptional response in the presence of exogenous melatonin. S. cerevisiae was able to incorporate exogenous melatonin, which affected genome-wide gene expression levels upon entering the cell. In the absence of stress, melatonin exposure appears to activate genes related to transport, oxidoreductase activity and hypoxia and to downregulate genes related to mitochondria and the ETC (mainly Complex III), triggering a hypoxia-like response, which could enhance fermentation performance. Indeed, some heme-dependent transcriptional regulators (Hap1p, Hap4p, Rox1p), together with the stress response factor Cin5p, seem to play a crucial role in the effect of melatonin at the transcriptional level. These changes in gene expression could also prepare yeast cells for coping with additional possible stresses such as oxidative stress. It is well established that under environmental stress conditions, the cellular machinery of yeast is reprogrammed to achieve better adaptation to stress, affecting not only genes involved in antioxidant defenses but also genes involved in lipid metabolism and reproduction. In this context, melatonin might enhance energetic efficiency and signal transduction, conferring higher $\mathrm{H}_{2} \mathrm{O}_{2}$ tolerance to $S$. cerevisiae. Under oxidative stress, melatonin upregulates genes related to antioxidant activity, cellular detoxification, oxidoreductase activity and the respiratory chain (mainly Complex IV), inducing transcriptional and physiological changes in yeast mitochondria. Thus, in stressed cells, melatonin supplementation seems to contribute to the stabilization of the mitochondrial electron chain, as observed in humans. However, as also shown in humans (reviewed in Cardinali and Vigo [22]) melatonin can play other roles in the yeast mitochondria: it increases the cardiolipin concentration and acts as a mitochondrion-targeted antioxidant at both physiological and transcriptional levels, activating genes related to mitochondrial function and maintenance.

Supplementary Materials: The following supplementary materials are available online at http://www.mdpi.com/ 2076-3921/9/10/947/s1, Figure S1: Genetic interactions analyzed by Phenetics (A) Mel vs. Control. (B) MelH vs. H; Table S1: Categories enriched according to GO analysis of the common genes identified in different comparisons, as shown in a Venn diagram (Figure 1); Table S2: Enriched pathways according to a KEGG database analysis of genes that were differentially expressed among cells in Mel vs. Control and in MelH vs. H; Table S3: Statistical results of the ANOVA test for the data in Figure 5. Table S4: Gene expression values representing the effect of melatonin on the nine selected genes in Mel vs. Control and MelH vs. h cells; Datasets S1-S10: Microarray analysis data of the different comparisons, statistics (moderated t-test) and annotations for each gene. Genes filtered with $p$-value < 0.05 (S1-S5) or no filtered by $p$-value (S6-S10): S1,S6: Mel vs Control; S2,S7: h vs. Control, S3,S8: MelH vs. Control; S4,S9: MelH vs. Control; S5,S10: 25MelH vs. MelH; Datasets S11-S19: Results of the GO enrichments [molecular function $(11,14,17)$, cellular component $(12,15,18)$ and biological process $(13,16,19)$ ] of the genes differentially expressed in Mel vs. Control (11-13), MelH vs. h (14-16), h vs. Control (17-19).

Author Contributions: Conceptualization, A.M., M.-J.T., and G.B.; Methodology, J.V. and M.S.-F.; Formal Analysis, J.V. and M.S.-F.; Investigation, J.V. and M.S.-F.; Resources, A.M., M.-J.T. and G.B.; Writing-Original Draft Preparation, J.V. and M.S.-F.; Writing-Review \& Editing, M.-J.T. and G.B.; Supervision, M.-J.T. and G.B.; Project Administration, A.M., M.-J.T. and G.B; Funding Acquisition, A.M., M.-J.T. and G.B. All authors have read and agreed to the published version of the manuscript.

Funding: This research was funded by the Ministry of Economy and Competitiveness, Spain, project numbers AGL2013-47300-C3-1-R and AGL2016-77505-C3-3-R; grant number FPU17/05475; and the University Rovira i Virgili, grant number 2013PMF-PIPF-18.

Acknowledgments: Authors thank the Centre for Omic Sciences (COS) for the transcriptomic determination and specially Pedro Nadal for his excellent technical assistance with the transcriptomic assay. They also thank Günther Daum for the collaboration with the lipid assays.

Conflicts of Interest: The authors declare no conflict of interest. 


\section{References}

1. Lerner, A.B.; Case, J.D.; Takahashi, Y.; Lee, T.H.; Mori, W. Isolation of melatonin, the pineal gland factor that Lightens melanocytes. J. Am. Chem. Soc. 1958, 80, 2587. [CrossRef]

2. Hardeland, R.; Poeggeler, B. Non-vertebrate melatonin. J. Pineal Res. 2003, 34, 233-241. [CrossRef] [PubMed]

3. Romero, A.; Ramos, E.; Ríos, C.D.L.; Egea, J.; Del Pino, J.; Reiter, R.J. A review of metal-catalyzed molecular damage: Protection by melatonin. J. Pineal Res. 2014, 56, 343-370. [CrossRef] [PubMed]

4. Eghbal, M.A.; Eftekhari, A.; Ahmadian, E.; Azarmi, Y.; Parvizpur, A. A review of biological and pharmacological actions of melatonin: oxidant and prooxidant properties. Pharm. Bioprocess. 2016, 4, 069-081. [CrossRef]

5. Sprenger, J.; Hardeland, R.; Fuhrberg, B.; Han, S.-Z. Melatonin and other 5-methoxylated indoles in yeast: presence in high concentrations and dependence on tryptophan availability. Cytologia 1999, 64, $209-213$. [CrossRef]

6. Rodriguez-Naranjo, M.I.; Gil-Izquierdo, A.; Troncoso, A.M.; Cantos-Villar, E.; Garcia-Parrilla, M.C. Melatonin is synthesised by yeast during alcoholic fermentation in wines. Food Chem. 2011, 126, 1608-1613. [CrossRef]

7. Rodriguez-Naranjo, M.I.; Torija, M.-J.; Mas, A.; Cantos-Villar, E.; Garcia-Parrilla, M.C. Production of melatonin by Saccharomyces strains under growth and fermentation conditions. J. Pineal Res. 2012, 53, 219-224. [CrossRef]

8. Vigentini, I.; Gardana, C.; Fracassetti, D.; Gabrielli, M.; Foschino, R.; Simonetti, P.; Tirelli, A.; Iriti, M. Yeast contribution to melatonin, melatonin isomers and tryptophan ethyl ester during alcoholic fermentation of grape musts. J. Pineal Res. 2015, 58, 388-396. [CrossRef]

9. Fernandez-Cruz, E.; Álvarez-Fernández, M.; Valero, E.; Troncoso, A.M.; Garcia-Parrilla, M.C. Melatonin and derived l-tryptophan metabolites produced during alcoholic fermentation by different wine yeast strains. Food Chem. 2017, 217, 431-437. [CrossRef]

10. Fernandez-Cruz, E.; Cerezo, A.B.; Cantos-Villar, E.; Troncoso, A.M.; Garcia-Parrilla, M.C. Time course of 1-tryptophan metabolites when fermenting natural grape musts: Effect of inoculation treatments and cultivar on the occurrence of melatonin and related indolic compounds. Aust. J. Grape Wine Res. 2018, 25, 92-100. [CrossRef]

11. Fernandez-Cruz, E.; González, B.; Muñiz-Calvo, S.; Morcillo-Parra, M.Á.; Bisquert, R.; Troncoso, A.M.; Garcia-Parrilla, M.C.; Torija, M.-J.; Guillamón, J.M. Intracellular biosynthesis of melatonin and other indolic compounds in Saccharomyces and non-Saccharomyces wine yeasts. Eur. Food Res. Technol. 2019, 245, 1553-1560. [CrossRef]

12. Valera, M.J.; Morcillo-Parra, M.Á.; Zagórska, I.; Mas, A.; Beltran, G.; Torija, M.-J. Effects of melatonin and tryptophol addition on fermentations carried out by Saccharomyces cerevisiae and non-Saccharomyces yeast species under different nitrogen conditions. Int. J. Food Microbiol. 2019, 289, 174-181. [CrossRef] [PubMed]

13. Muñiz-Calvo, S.; Bisquert, R.; Fernandez-Cruz, E.; García-Parrilla, M.C.; Guillamón, J.M. Deciphering the melatonin metabolism in Saccharomyces cerevisiae by the bioconversion of related metabolites. J. Pineal Res. 2019, 66, e12554. [CrossRef] [PubMed]

14. Bisquert, R.; Muñiz-Calvo, S.; Guillamón, J.M. Protective role of intracellular melatonin against oxidative stress and UV radiation in Saccharomyces cerevisiae. Front. Microbiol. 2018, 9, 318. [CrossRef] [PubMed]

15. Vázquez, J.; Grillitsch, K.; Daum, G.; Mas, A.; Torija, M.-J.; Beltran, G. Melatonin minimizes the impact of oxidative stress induced by hydrogen peroxide in Saccharomyces and non-conventional yeast. Front. Microbiol. 2018, 9, 1933. [CrossRef]

16. Vázquez, J.; González, B.; Sempere, V.; Mas, A.; Torija, M.J.; Beltran, G. Melatonin reduces oxidative stress damage induced by hydrogen peroxide in Saccharomyces cerevisiae. Front. Microbiol. 2017, 8, 1066. [CrossRef]

17. Morcillo-Parra, M.Á.; Valera, M.J.; Beltran, G.; Mas, A.; Torija, M.-J. Glycolytic proteins interact with intracellular melatonin in Saccharomyces cerevisiae. Front. Microbiol. 2019, 10, 2424. [CrossRef]

18. Morcillo-Parra, M.Á.; González, B.; Beltran, G.; Mas, A.; Torija, M.-J. Melatonin and glycolytic protein interactions are related to yeast fermentative capacity. Food Microbiol. 2020, 87, 103398. [CrossRef]

19. Moradas-Ferreira, P.; Costa, V. Adaptive response of the yeast Saccharomyces cerevisiae to reactive oxygen species: Defences, damage and death. Redox Rep. 2000, 5, 277-285. [CrossRef]

20. Costa, V. Oxidative stress and signal transduction in Saccharomyces cerevisiae: Insights into ageing, apoptosis and diseases. Mol. Asp. Med. 2001, 22, 217-246. [CrossRef]

21. Jamieson, D.J. Oxidative stress responses of the yeast Saccharomyces cerevisiae. Yeast 1998, 14, 1511-1527. [CrossRef] 
22. Cardinali, D.P.; Vigo, D.E. Melatonin, mitochondria, and the metabolic syndrome. Cell. Mol. Life Sci. 2017, 74, 3941-3954. [CrossRef]

23. Reiter, R.J.; Ma, Q.; Sharma, R. Melatonin in Mitochondria: Mitigating Clear and Present Dangers. Physiology 2020, 35, 86-95. [CrossRef] [PubMed]

24. Zampol, M.A.; Barros, M.H. Melatonin improves survival and respiratory activity of yeast cells challenged by alpha-synuclein and menadione. Yeast 2017, 35, 281-290. [CrossRef] [PubMed]

25. Causton, H.C.; Ren, B.; Koh, S.S.; Harbison, C.T.; Kanin, E.; Jennings, E.G.; Lee, T.I.; True, H.L.; Lander, E.S.; Young, R.A. Remodeling of yeast genome expression in response to environmental changes. Mol. Boil. Cell 2001, 12, 323-337. [CrossRef] [PubMed]

26. Thorpe, G.W.; Fong, C.S.; Alic, N.; Higgins, V.J.; Dawes, I.W. Cells have distinct mechanisms to maintain protection against different reactive oxygen species: Oxidative-stress-response genes. Proc. Natl. Acad. Sci. USA 2004, 101, 6564-6569. [CrossRef] [PubMed]

27. Zhao, H.; Chen, J.; Liu, J.; Han, B. Transcriptome analysis reveals the oxidative stress response in Saccharomyces cerevisiae. RSC Adv. 2015, 5, 22923-22934. [CrossRef]

28. Gonzalez, B.; François, J.; Renaud, M. A rapid and reliable method for metabolite extraction in yeast using boiling buffered ethanol. Yeast 1997, 13, 1347-1355. [CrossRef]

29. De Maeyer, D.; Weytjens, B.; Renkens, J.; De Raedt, L.; Marchal, K. PheNetic: Network-based interpretation of molecular profiling data. Nucleic Acids Res. 2015, 43, W244-W250. [CrossRef]

30. Carbon, S.; Ireland, A.; Mungall, C.J.; Shu, S.; Marshall, B.; Lewis, S. AmiGO: Online access to ontology and annotation data. Bioinformatics 2008, 25, 288-289. [CrossRef]

31. Kanehisa, M.; Goto, S.; Kawashima, S.; Nakaya, A. The KEGG databases at GenomeNet. Nucleic Acids Res. 2002, 30, 42-46. [CrossRef] [PubMed]

32. Huang, D.W.; Sherman, B.T.; Lempicki, R.A. Bioinformatics enrichment tools: Paths toward the comprehensive functional analysis of large gene lists. Nucleic Acids Res. 2008, 37, 1-13. [CrossRef] [PubMed]

33. Huang, D.W.; Sherman, B.T.; Lempicki, R.A. Systematic and integrative analysis of large gene lists using DAVID bioinformatics resources. Nat. Protoc. 2009, 4, 44-57. [CrossRef] [PubMed]

34. Beltran, G.; Novo, M.; Rozès, N.; Mas, A.; Guillamón, J.M. Nitrogen catabolite repression in during wine fermentations. FEMS Yeast Res. 2004, 4, 625-632. [CrossRef] [PubMed]

35. Teste, M.-A.; Duquenne, M.; François, J.M.; Parrou, J.-L. Validation of reference genes for quantitative expression analysis by real-time RT-PCR in Saccharomyces cerevisiae. BMC Mol. Boil. 2009, 10, 99. [CrossRef]

36. Vázquez, J.; Grillitsch, K.; Daum, G.; Mas, A.; Beltran, G.; Torija, M.J. The role of the membrane lipid composition in the oxidative stress tolerance of different wine yeasts. Food Microbiol. 2019, 78, 143-154. [CrossRef]

37. Folch, J.; Lees, M.; Sloane Stanley, G.H. A simple method for the isolation and purification of total lipides from animal tissues. J. Biol. Chem. 1957, 226, 497-509. [CrossRef]

38. Quail, M.A.; Kelly, S.L.; Evans, I.H. The extraction and analysis of sterols from yeast. In Yeast Protocols. Methods in Molecular Biology; Evans, I.H., Ed.; Humana Press: New York, NY, USA, 1996; Volume 53, pp. 123-132.

39. Rußmayer, H.; Buchetics, M.; Gruber, C.; Valli, M.; Grillitsch, K.; Modarres, G.; Guerrasio, R.; Klavins, K.; Neubauer, S.; Drexler, H.; et al. Systems-level organization of yeast methylotrophic lifestyle. BMC Boil. 2015, 13, 80. [CrossRef]

40. Athenstaedt, K.; Zweytick, D.; Jandrositz, A.; Kohlwein, S.D.; Daum, G. Identification and characterization of major lipid Particle Proteins of the Yeast Saccharomyces cerevisiae. J. Bacteriol. 1999, 181, 6441-6448. [CrossRef]

41. Broekhuyse, R. Phospholipids in tissues of the eye I. Isolation, characterization and quantitative analysis by two-dimensional thin-layer chromatography of diacyl and vinyl-ether phospholipids. Biochim. Biophys. Acta 1968, 152, 307-315. [CrossRef]

42. Boettiger, D.; Huber, F.; Lynch, L.; Blystone, S. Activation of $\alpha v \beta 3$-Vitronectin Binding Is a Multistage Process in which Increases in Bond Strength Are Dependent on Y747 and Y759 in the Cytoplasmic Domain of $\beta 3$. Mol. Boil. Cell 2001, 12, 1227-1237. [CrossRef]

43. Slominski, R.M.; Reiter, R.J.; Schlabritz-Loutsevitch, N.; Ostrom, R.S.; Slominski, A.T. Melatonin membrane receptors in peripheral tissues: Distribution and functions. Mol. Cell. Endocrinol. 2012, 351, 152-166. [CrossRef] [PubMed] 
44. Galano, A.; Tan, D.X.; Reiter, R.J. Melatonin as a natural ally against oxidative stress: A physicochemical examination. J. Pineal Res. 2011, 51,1-16. [CrossRef] [PubMed]

45. Hevia, D.; Gonzalez-Menendez, P.; Quirós-Gonzalez, I.; Miar, A.; Rodriguez-Garcia, A.; Tan, D.-X.; Reiter, R.J.; Mayo, J.C.; Sainz, R.M. Melatonin uptake through glucose transporters: A new target for melatonin inhibition of cancer. J. Pineal Res. 2015, 58, 234-250. [CrossRef] [PubMed]

46. Huo, X.; Wang, C.; Yu, Z.; Peng, Y.; Wang, S.; Feng, S.; Zhang, S.; Tian, X.; Sun, C.-P.; Liu, K.; et al. Human transporters, PEPT1/2, facilitate melatonin transportation into mitochondria of cancer cells: An implication of the therapeutic potential. J. Pineal Res. 2017, 62, e12390. [CrossRef] [PubMed]

47. Mayo, J.C.; Aguado, A.; Cernuda-Cernuda, R.; Alvarez-Artime, A.; Cepas, V.; Quirós-González, I.; Hevia, D.; Sainz, R.M. Melatonin uptake by cells: An answer to its relationship with glucose? Molecules 2018, 23, 1999. [CrossRef] [PubMed]

48. Reiter, R.J.; Tan, D.-X.; Terron, M.P.; Flores-Alvarado, L.J.; Czarnocki, Z. Melatonin and its metabolites: New findings regarding their production and their radical scavenging actions. Acta Biochim. Pol. 2007, 54, 1-9. [CrossRef]

49. Rodriguez, C.; Mayo, J.C.; Sainz, R.M.; Antolín, I.; Herrera, F.; Martín, V.; Reiter, R.J. Regulation of antioxidant enzymes: A significant role for melatonin. J. Pineal Res. 2004, 36, 1-9. [CrossRef]

50. Folmer, V.; Pedroso, N.; Matias, A.C.; Lopes, S.C.; Antunes, F.; Cyrne, M.L.; Marinho, H.S. $\mathrm{H}_{2} \mathrm{O}_{2}$ induces rapid biophysical and permeability changes in the plasma membrane of Saccharomyces cerevisiae. Biochim. Biophys. Acta 2008, 1778, 1141-1147. [CrossRef]

51. Henderson, C.M.; Block, D.E. Examining the role of membrane lipid composition in determining the ethanol tolerance of Saccharomyces cerevisiae. Appl. Environ. Microbiol. 2014, 80, 2966-2972. [CrossRef]

52. Joshua, I.M.; Höfken, T. From lipid homeostasis to differentiation: Old and new functions of the zinc cluster proteins Ecm22, Upc2, Sut1 and Sut2. Int. J. Mol. Sci. 2017, 18, 772. [CrossRef] [PubMed]

53. Zavrel, M.; Hoot, S.J.; White, T.C. Comparison of sterol import under aerobic and anaerobic conditions in three fungal species, Candida albicans, Candida glabrata, and Saccharomyces cerevisiae. Eukaryot. Cell 2013, 12, 725-738. [CrossRef] [PubMed]

54. Serrazanetti, D.I.; Patrignani, F.; Russo, A.; Vannini, L.; Siroli, L.; Gardini, F.; Lanciotti, R. Cell membrane fatty acid changes and desaturase expression of Saccharomyces bayanus exposed to high pressure homogenization in relation to the supplementation of exogenous unsaturated fatty acids. Front. Microbiol. 2015, 6, 1105. [CrossRef]

55. Allan, K.M.; Loberg, M.A.; Chepngeno, J.; Hurtig, J.E.; Tripathi, S.; Kang, M.G.; Allotey, J.K.; Widdershins, A.H.; Pilat, J.M.; Sizek, H.J.; et al. Trapping redox partnerships in oxidant-sensitive proteins with a small, thiol-reactive cross-linker. Free. Radic. Boil. Med. 2016, 101, 356-366. [CrossRef]

56. Biteau, B.; Labarre, J.; Toledano, M.B. ATP-Dependent Reduction of Cysteine-Sulphinic Acid by S. cerevisiae Sulphiredoxin. Nature 2003, 425, 980-984. [CrossRef] [PubMed]

57. Zhang, M.; Zhang, K.; Mehmood, M.A.; Zhao, Z.K.; Bai, F.; Zhao, X. Deletion of acetate transporter gene ADY2 improved tolerance of Saccharomyces cerevisiae against multiple stresses and enhanced ethanol production in the presence of acetic acid. Bioresour. Technol. 2017, 245, 1461-1468. [CrossRef] [PubMed]

58. Alonso-González, C.; Mediavilla, D.; Martínez-Campa, C.; González, A.; Cos, S.; Sanchez-Barcelo, E.J. Melatonin modulates the cadmium-induced expression of MT-2 and MT-1 metallothioneins in three lines of human tumor cells (MCF-7, MDA-MB-231 and HeLa). Toxicol. Lett. 2008, 181, 190-195. [CrossRef]

59. Reiter, R.J.; Mayo, J.C.; Tan, D.-X.; Sainz, R.M.; Alatorre-Jimenez, M.; Qin, L. Melatonin as an antioxidant: under promises but over delivers. J. Pineal Res. 2016, 61, 253-278. [CrossRef]

60. Gasch, A.P.; Spellman, P.T.; Kao, C.M.; Carmel-Harel, O.; Eisen, M.B.; Storz, G.; Botstein, D.; Brown, P.O. Genomic expression programs in the response of yeast cells to environmental changes. Mol. Boil. Cell 2000, 11, 4241-4257. [CrossRef]

61. Boyle, G.M.; Roucou, X.; Nagley, P.; Devenish, R.J.; Prescott, M. Identification of subunit g of yeast mitochondrial F1F0-ATP synthase, a protein required for maximal activity of cytochrome c oxidase. JBIC J. Boil. Inorg. Chem. 1999, 262, 315-323. [CrossRef]

62. Acuña-Castroviejo, D.; Escames, G.; León, J.; Carazo, A.; Khaldy, H. Mitochondrial regulation by melatonin and its metabolites. In Developments in Tryptophan and Serotonin Metabolism. Advances in Experimental Medicine and Biology; Allegri, G., Costa, C.V.L., Ragazzi, E., Steinhart, H., Varesio, L., Eds.; Springer: Boston, MA, USA, 2003; Volume 527, pp. 549-557. [CrossRef] 
63. Petrosillo, G.; De Benedictis, V.; Ruggiero, F.M.; Paradies, G. Decline in cytochrome c oxidase activity in rat-brain mitochondria with aging. Role of peroxidized cardiolipin and beneficial effect of melatonin. J. Bioenerg. Biomembr. 2013, 45, 431-440. [CrossRef] [PubMed]

64. Xia, Y.; Chen, S.; Zeng, S.; Zhao, Y.; Zhu, C.; Deng, B.; Zhu, G.; Yin, J.; Wang, W.; Hardeland, R.; et al. Melatonin in macrophage biology: Current understanding and future perspectives. J. Pineal Res. 2019, 66, e12547. [CrossRef] [PubMed]

65. Martin, M.; Macias, M.; Escames, G.; Reiter, R.; Agapito, M.; Ortiz, G.; Acuña-Castroviejo, D. Melatonin-induced increased activity of the respiratory chain complexes I and IV can prevent mitochondrial damage induced by ruthenium red in vivo. J. Pineal Res. 2000, 28, 242-248. [CrossRef] [PubMed]

66. Bode, M.; Longen, S.; Morgan, B.; Peleh, V.; Dick, T.P.; Bihlmaier, K.; Herrmann, J.M. Inaccurately assembled cytochrome c oxidase can lead to oxidative stress-induced growth arrest. Antioxidants Redox Signal. 2013, 18, 1597-1612. [CrossRef]

67. Piccoli, C.; Scrima, R.; Boffoli, D.; Capitanio, N. Control by cytochrome c oxidase of the cellular oxidative phosphorylation system depends on the mitochondrial energy state. Biochem. J. 2006, 396, 573-583. [CrossRef]

68. Srinivasan, S.; Avadhani, N.G. Cytochrome c oxidase dysfunction in oxidative stress. Free. Radic. Boil. Med. 2012, 53, 1252-1263. [CrossRef]

69. Büyükavci, M.; Özdemir, Ö.; Buck, S.; Stout, M.; Ravindranath, Y.; Savaşan, S. Melatonin cytotoxicity in human leukemia cells: Relation with its pro-oxidant effect. Fundam. Clin. Pharmacol. 2006, 20, 73-79. [CrossRef]

70. Osseni, R.A.; Rat, P.; Bogdan, A.; Warnet, J.-M.; Touitou, Y. Evidence of prooxidant and antioxidant action of melatonin on human liver cell line HepG2. Life Sci. 2000, 68, 387-399. [CrossRef]

71. Bejarano, I.; Espino, J.; Barriga, C.; Reiter, R.J.; Pariente, J.A.; Rodríguez, A.B. Pro-Oxidant effect of melatonin in tumour Leucocytes: Relation with its cytotoxic and pro-apoptotic effects. Basic Clin. Pharmacol. Toxicol. 2010, 108, 14-20. [CrossRef]

72. Zhang, H.-M.; Zhang, Y.-Q.; Zhang, B.-X. The role of mitochondrial complex III in melatonin-induced ROS production in cultured mesangial cells. J. Pineal Res. 2010, 50, 78-82. [CrossRef]

73. Hardeland, R. Melatonin and the electron transport chain. Cell. Mol. Life Sci. 2017, 74, 3883-3896. [CrossRef] [PubMed]

74. Weidberg, H.; Amon, A. MitoCPR-A surveillance pathway that protects mitochondria in response to protein import stress. Science 2018, 360, eaan4146. [CrossRef]

75. Kolaczkowska, A.; Goffeau, A. Regulation of pleiotropic drug resistance in yeast. Drug Resist. Updat. 1999, 2, 403-414. [CrossRef] [PubMed]

76. Tan, D.-X.; Manchester, L.C.; Qin, L.; Reiter, R.J. Melatonin: A mitochondrial targeting molecule involving mitochondrial protection and dynamics. Int. J. Mol. Sci. 2016, 17, 2124. [CrossRef] [PubMed]

77. Rodrigues-Pousada, C.; Menezes, R.; Pimentel, C. The Yap family and its role in stress response. Yeast 2010, 27, 245-258. [CrossRef] [PubMed]

78. Rodrigues-Pousada, C.; Devaux, F.; Caetano, S.M.; Pimentel, C.; Da Silva, S.; Cordeiro, A.C.; Amaral, C. Yeast AP-1 like transcription factors (Yap) and stress response: A current overview. Microb. Cell 2019, 6, 267-285. [CrossRef] [PubMed]

79. MacIsaac, K.D.; Wang, T.; Gordon, D.B.; Gifford, D.K.; Stormo, G.D.; Fraenkel, E. An improved map of conserved regulatory sites for Saccharomyces cerevisiae. BMC Bioinform. 2006, 7, 113. [CrossRef]

80. Hu, Z.; Killion, P.J.; Iyer, V.R. Genetic reconstruction of a functional transcriptional regulatory network. Nat. Genet. 2007, 39, 683-687. [CrossRef]

81. Batova, M.; Klobučníková, V.; Oblasova, Z.; Gregáň, J.; Zahradnik, P.; Hapala, I.; Šubík, J.; Schüller, C. Chemogenomic and transcriptome analysis identifies mode of action of the chemosensitizing agent CTBT (7-chlorotetrazolo[5,1-c]benzo[1,2,4]triazine). BMC Genom. 2010, 11, 153. [CrossRef]

82. Liu, H.; Styles, C.; Fink, G. Elements of the yeast pheromone response pathway required for filamentous growth of diploids. Science 1993, 262, 1741-1744. [CrossRef]

83. Borneman, A.R.; Leigh-Bell, J.A.; Yu, H.; Bertone, P.; Gerstein, M.; Snyder, M. Target hub proteins serve as master regulators of development in yeast. Genes Dev. 2006, 20, 435-448. [CrossRef] [PubMed]

84. González, B.; Vázquez, J.; Cullen, P.J.; Mas, A.; Beltran, G.; Torija, M.J. Aromatic Amino Acid-Derived Compounds Induce Morphological Changes and Modulate the Cell Growth of Wine Yeast Species. Front. Microbiol. 2018, 9, 670. [CrossRef] [PubMed] 
85. Chen, H.; Fink, G.R. Feedback control of morphogenesis in fungi by aromatic alcohols. Genes Dev. 2006, 20, 1150-1161. [CrossRef] [PubMed]

86. Siso, M.I.G.; Becerra, M.; Maceiras, M.L.; Vizoso-Vázquez, Á.; Cerdán, M. The yeast hypoxic responses, resources for new biotechnological opportunities. Biotechnol. Lett. 2012, 34, 2161-2173. [CrossRef]

87. Lee, S.K.; Chen, X.; Huang, L.; Stargell, L.A. The head module of Mediator directs activation of preloaded RNAPII in vivo. Nucleic Acids Res. 2013, 41, 10124-10134. [CrossRef] [PubMed]

88. Lorenz, R.T.; Parks, L.W. Regulation of ergosterol biosynthesis and sterol uptake in a sterol-auxotrophic yeast. J. Bacteriol. 1987, 169, 3707-3711. [CrossRef] [PubMed]

89. Abramova, N.; Sertil, O.; Mehta, S.; Lowry, C.V. Reciprocal regulation of anaerobic and aerobic cell wall mannoprotein gene expression in Saccharomyces cerevisiae. J. Bacteriol. 2001, 183, 2881-2887. [CrossRef]

90. Bendjilali, N.; MacLeon, S.; Kalra, G.; Willis, S.D.; Hossian, A.K.M.N.; Avery, E.; Wojtowicz, O.; Hickman, M. Time-course analysis of gene expression during the Saccharomyces cerevisiae hypoxic response. G3 Genes Genome Genet. 2016, 7, 221-231. [CrossRef]

91. Miura, N.; Shinohara, M.; Tatsukami, Y.; Sato, Y.; Morisaka, H.; Kuroda, K.; Ueda, M. Spatial reorganization of Sacharomyces cerevisiae enolase to alter carbon metabolism under hypoxia. Eukaryot. Cell 2013, 12, 1106-1119. [CrossRef]

(C) 2020 by the authors. Licensee MDPI, Basel, Switzerland. This article is an open access article distributed under the terms and conditions of the Creative Commons Attribution (CC BY) license (http://creativecommons.org/licenses/by/4.0/). 